\title{
Cyclic behavior of Peruvian confined masonry walls and calibration of numerical model using genetic algorithms
}

\author{
Luis G. QUIROZ ${ }^{\dagger, a}$, Yoshihisa MARUYAMA ${ }^{\dagger}$ and Carlos ZAVALA ${ }^{\ddagger}$ \\ ${ }^{\dagger}$ Department of Urban Environment Systems, Chiba University, 1-33 Yayoi-cho, Inage-ku, \\ Chiba 263-8522, Japan \\ *Japan-Peru Center for Earthquake Engineering Research and Disaster Mitigation, National \\ University of Engineering, Tupac Amaru Avenue 1150, Lima 25, Peru
}

\begin{abstract}
The experimental results of four full-scale confined masonry (CM) walls subjected to cycling loading are presented. These structural elements are widely used in low- and mid-rise buildings in Peru to take the vertical and lateral loads. The objective of these experiments was to evaluate the cyclic behavior of CM walls constructed with handmade bricks and mortar. The brick units used in the walls were made of clay, and they were considered to be solid components. In the experiment, the dimensions of all the walls were kept constant in all specimens, but the reinforcement ratios of the confining elements (bond beam and tie-columns) were changed. The structural behaviors were examined in terms of the strength, lateral stiffness, dissipated energy, and equivalent viscous damping. Finally, an equivalent macro-model based on an equivalent strut approach with a smooth hysteretic model was calibrated and validated in order to reproduce the behaviors of the CM walls. For this purpose, we used a genetic algorithm (GA) that considered the experimental results of a CM wall. The parameters were applied to the results of the other CM walls to evaluate their applicability. The results of numerical simulations showed good agreement with the experimental results.
\end{abstract}

Keywords: confined masonry wall, cyclic loading, full-scale test, equivalent strut approach, smooth hysteretic model

\footnotetext{
${ }^{\mathrm{a}}$ Correspondence should be sent to Luis G. QUIROZ, Department of Urban Environment Systems, Chiba University, 1-33 Yayoi-cho, Inage-ku, Chiba 263-8522, Japan

Tel.: +81-43-292-3528, Fax: +81-43-292-3558

E-mail: lgquiroz@uni.edu.pe
} 


\section{INTRODUCTION}

Masonry is one of the most widely used materials for the walls of dwellings in Peru, especially in Lima. However, the inherent weakness of masonry in tension has been repeatedly observed during seismic events around the world. The need to overcome the seismic deficiency of unreinforced masonry (URM) walls has led to the development of structural walls with different reinforcement patterns. From the structural and seismic points of view, masonry can generally be used in two ways for dwellings: confined or reinforced masonry and reinforced-concrete (RC) frames with masonry infill. Confined masonry (CM) walls consist of URM walls confined with RC tie-columns and bond beams. Walls of this type are used in both urban and rural areas for low- and mid-rise dwellings because they can be constructed with a low cost compared with other structural systems (e.g., RC frames and RC walls). With the increased popularity and availability of RC and different types of masonry units, this construction is common in many countries, including Peru, Chile, Argentina, Mexico, Iran, Slovenia, according to the World Housing Encyclopedia [1]. CM walls are often used as structural elements to provide resistance to gravitational and seismic lateral loads. This type of construction seems to have more strength, ductility, and stiffness than URM walls, and it showed better seismic performance during recent earthquakes.

Lima City has not been hit by a big earthquake since 1974 . The last big earthquake that occurred in Peru was the Pisco, Peru earthquake of August 15, 2007 ( $\mathrm{Mw}=8.0$ ), which caused severe damage to masonry constructions. Under these circumstances, it is expected that masonry constructions that are properly built according to the requirements of the design standard for masonry structures [2] will show better seismic performances. In Peru, the first regulations for masonry seismic design appeared in 1977. Then, in 1982, the first masonry design standard (E.070) was issued. Because of the small amount of experimental data available, the design of the walls was performed in an elastic range considering allowable stresses. Research programs have been developed by both the Japan-Peru Center for Earthquake Engineering Research and Disaster Mitigation (CISMID) of the National University of Engineering (UNI) and the Pontifical Catholic University of Peru (PUCP) to bring about a better understanding of the behavior of masonry walls. For many years, researchers studied the materials (brick units, mortar), effects of the reinforcement of confining elements and walls, effects of vertical loads, types of connections between panels and tie-columns, effects of slenderness, and various other aspects. Some of the results of these studies can be found in the literature [3]. Based on recent studies and the lessons learned from 
past earthquakes in Peru and other countries, a new masonry design standard was proposed in 2001. This new masonry design standard (E.070) [2] was issued in 2006, and it defines the performance criteria.

Several other studies have been carried out around the world on structural elements or entire structures to increase the understanding of the behavior of masonry walls or to improve standards. These studies have considered variations in the characteristics or configurations of the components (e.g., the characteristics of bricks, confining elements, etc.). Several of these studies are reviewed below. Decanini et al. [4] tested eight CM panels subjected to the effects of horizontal loads simulating seismic motion in the laboratory of the National University of Cordoba, Argentina. Four of these masonry panels were made of solid clay bricks, and the others were made of hollow clay bricks. They found that the walls made of hollow clay bricks showed 20\% more strength against ultimate cracking than against initial cracking. In 1999, Alcocer and Zepeda [5] analyzed the test results of four isolated large-scale multi-perforated clay brick walls under constant vertical axial loads and cyclic lateral loads in order to evaluate their behaviors and develop analysis, design, and construction guidelines. Irimies [6] studied the influence of both the confining of un-reinforced masonry walls and the vertical reinforcement ratio in tie-columns on the seismic behavior of the masonry walls in three half-scale two-story specimens. One of these was an un-reinforced masonry wall, and the others were CM walls. The wall models were tested under lateral cyclic loading in the presence of a constant vertical force. It was found that increasing the amount of vertical reinforcement in the tie-columns by 1.8 times enhanced the lateral strength by approximately 20\%. Meli [7] presented test results for CM walls and assessed the responses in terms of strength, ductility, and energy absorption. Yoshimura et al. [8] studied CM walls and their nonlinear characteristics when lateral reinforcement is employed for the mortar joints at the corner part of the wall. Marinilli and Castilla [9] evaluated the effects of the number of vertical confining elements on the seismic behavior of $\mathrm{CM}$ walls by using four specimens. The walls were tested under cyclic lateral loads and a constant vertical load. The results showed how the number of confining-columns affected the stiffness degradation, energy dissipation capacity, ductility, cracking pattern, and strength of the walls. An important aspect of the wall performance is the openings, which were studied by Yañez et al. [10]. They found that walls with an opening ratio of around $11 \%$ of the total area of the wall presented similar stiffness as walls without openings. In 2007, Gouveia and Lourenco [11] studied the effects of confinement, horizontal reinforcement, and different kinds of brick units on the response of 
CM walls. Tena-Colunga et al. [12] presented a complete experimental protocol for combined and CM walls. They found that combined and CM walls jointed with non-engineered mortar did not satisfy all the criteria to be qualified as earthquake resistant walls. In contrast, the combined and CM walls jointed with engineered mortar showed a performance (cracking patterns, initial stiffness, cracking drift angle, drift angle for design, etc.) equivalent to the experimental results for similar CM walls made with solid clay bricks. Wijaya et al. [13] studied the influence of the type of connection between the wall panel and RC elements (e.g., grooves at interface of masonry and tie column, continuous anchorage embedded in mortar joint and RC elements). They investigated a reinforced concrete frame with masonry infill. Recently, Torrisi et al. [14] found that a structural separation occurs between a masonry panel and the confining elements at the initial stages of loading for both CM and infill walls. They also observed the formation of a compression stress field in a masonry panel using experimental data and numerical simulations. Recently, research on the seismic performance of CM walls with hollow and tubular brick units and improvement of their structural performance has been carried out in Peru $[15,16]$.

In spite of the masonry experimental research programs conducted in many countries [4-14], the behavior of CM walls is still not well known [10], and the results tend to be for the characteristics of structural systems related to regional situations (e.g., construction process, quality of labor, material properties). As noted above, the available information on CM walls in the case of Peru is limited. Hence, continuing with the experimental study of CM walls in countries where they are widely used like in Peru is important. In the present study, the results of experiments carried out in Lima, Peru, at CISMID in 2003 [17] will be investigated using their structural characteristics and a numerical simulation. Later, based on the experimental results, an equivalent strut approach with a smooth hysteretic model is calibrated, and validation of the numerical simulation is discussed. The walls employed in this study were the typical type of walls used in low- and mid-rise Peruvian dwellings.

\section{DESCRIPTION OF FULL-SCALE EXPERIMENT}

A series of tests were carried out on CM walls in 2003 with different reinforcement ratios in the tie-columns and bond beams. The walls were cast at full scale with the same geometrical properties. An important parameter that governs the damage pattern and failure mode is the aspect ratio (height-to-length ratio). The $\mathrm{h}_{\mathrm{w}} / \mathrm{l}_{\mathrm{w}}$ ratio was set to 0.906 . Squat $\mathrm{CM}$ walls with an aspect ratio of around 1 are commonly used in practice [18]. These walls were 
subjected to slow cyclic horizontal loading. The responses of four walls were studied in terms of the elastic stiffness and maximum strength [17].

\subsection{Description of specimens}

Four walls were constructed and tested under cyclic lateral loading. The walls were divided into two groups, with each group containing two specimens. The first group was called A1, and the specimens were named A1-1 and A1-2. Similar denominations were used for the second group. The difference between the two specimens of the first group was the reinforcement ratio used in the bond beams. In the case of the second group, the difference was the reinforcement ratio of the tie-columns. In both groups, the transversal reinforcement of the confining elements was kept constant.

The geometry of the walls is schematically shown in Fig. 1(a). The general dimensions of the walls and their confinement elements were set to be as close as possible to the dimensions of a CM wall used in low- and mid-rise dwellings.

The nominal dimensions of all the specimens were a total height of $2400 \mathrm{~mm}$, total length of $2650 \mathrm{~mm}$, and thickness of $205 \mathrm{~mm}$. The specimens were monolithically connected to a foundation, which was used to fix the wall to the floor in order to consider a fully fixed footing. The nominal dimensions of this foundation were a width of $800 \mathrm{~mm}$ and a height of $300 \mathrm{~mm}$. The characteristics of the confining elements are as follows. The tie-column elements were $300 \times 230 \mathrm{~mm}$ in size, with the reinforcement presented in Table 1 . The bond beam elements were $300 \times 200 \mathrm{~mm}$ in size, with different reinforcements, which are also specified in Table 1. Figure 1(b) depicts the arrangement of the reinforcements in the confining elements for specimen A1-1. The distributions of the reinforcements in the other specimens were similar. Additionally, Fig. 1(b) shows the transversal reinforcement of the confining elements.

The compressive strength of the concrete used for the confining tie-columns and bond beams was $\mathrm{f}^{\prime}{ }_{\mathrm{c}}=20.6 \mathrm{MPa}$, according to the tests carried out on cylindrical specimens of 150 $\mathrm{mm} \times 300 \mathrm{~mm}$. The coefficient of variation for $\mathrm{f}^{\prime}{ }_{\mathrm{c}}$ was not reported in [17]. Young's modulus of concrete $\left(E_{c}\right)$ was set to $21302 \mathrm{MPa}$. The bars yielded under a tensile stress $\left(f_{y}\right)$ of approximately $411.6 \mathrm{MPa}$, with an associated strain $\left(\varepsilon_{y}\right)$ of 0.002 . The maximum stress $\left(f_{u}\right)$ and hardening strain $\left(\varepsilon_{h}\right)$ were set to $783.27 \mathrm{MPa}$ and 0.006 , respectively.

The brick units used in the tests were made from clay by hand; they can be considered as solid units because they did not present holes in the bed area. According to the design 
standards, the use of hollow units (i.e., units that present more than $30 \%$ holes in the bed area) in structural walls is prohibited [2]. The solid handmade brick units were employed for wall specimens because the previous studies investigated the response characteristics of factory-made brick units [3], and hollow brick units [4]. In addition, handmade brick units are often used in expansion areas of the urban zones in Lima, and they do not have good resistance compared to factory-made brick units. A set of masonry prisms was constructed to define the compressive strength $\left(f^{\prime}{ }_{m}\right)$ and Young's modulus $\left(E_{m}\right)$ for the masonry, following the general guidelines and requirements provided by the previous design standard (E.070) [19]. Both bed and head joints were filled with $10 \mathrm{~mm}$ thick mortar. The mortar was measured by volume using a 1:4 cement-coarse sand proportion. The mechanical properties of the mortar and brick units were not previously described in [17]. Figure 2 shows a sample of a prism, and Table 2 presents a summary of the experimental results. The values of $f^{\prime}{ }_{m}$ and $E_{m}$ were estimated following the requirements of the current standard (E.070) [2]. This standard stipulates that the characteristic resistance in piles $f^{\prime}{ }_{m}$ must be obtained as the average value of the samples minus one standard deviation. The value of $E_{m}$ was estimated to be $500 f^{\prime} m$ according to the standard specifications given a value of $1870 \mathrm{MPa}$. The experimental results for prisms show that $f^{\prime}{ }_{m}$ was around the value specified by the design standard [3] in the case of handmade units. Because of the lack of diagonal compression tests for low walls, the resistance to shear $\left(v_{m}^{\prime}\right)$ was set to $0.5 \mathrm{MPa}$, as suggested in the design standard [3]. This decision was made because the compression test on the prism obtained a value of $f_{m}^{\prime}$ very close to that suggested by the masonry design standard for handmade bricks.

\subsection{Instrumentation and loading frame}

The instrumentation of the specimens with force transducers and displacement transducers (LVDTs) made it possible to monitor the loads and in-plane displacements. To support these devices, a steel frame was built around each specimen. This steel frame was also used as a reaction frame for a vertical actuator that applied a confinement load to the specimens. A reaction wall was used as a support for a lateral electro-hydraulic actuator of $\pm 490 \mathrm{kN}$, with the capacity to produce displacements of $\pm 200 \mathrm{~mm}$. This actuator was controlled by a Shimadzu 9525 controller and a personal computer with an analog-to-digital and digital-to-analog signal conversion card. The behaviors of the walls were monitored through the sensors connected to a signal conditioner that transferred the data to a computer for every measurement step. The working range of the LVDTs was 10 to $200 \mathrm{~mm}$. Figure 3(a) 
shows the positions of the LVDTs on the specimens, and Fig. 3(b) shows the load application scheme.

\subsection{Loading history and testing procedure}

Prior to the application of the lateral load, a vertical load of approximately $78.45 \mathrm{kN}$ was applied through an electro-hydraulic actuator. This load represented the weight that should be expected at the bottom of a central wall in a two-story building, and it was kept constant throughout the tests.

Unlike other countries such as Mexico [12], Peru has no regulations on the protocol for testing CM walls. Thus, in order to simulate the loading expected during an earthquake, a simple horizontal cyclic loading history with small increments was employed. The horizontal loading was applied at a quasi-static rate with the cycles controlled by the displacement. The location of this horizontal load was the center of the bond beam at the top of the wall.

Table 3 lists the numbers of phases and cycles applied to the walls and also their respective target displacements at the top. When the target displacement was generated, the force was kept constant to assess the distribution and widths of the cracks. Then, the specimens were gradually unloaded. Six phases were applied, each of which consisted of two cycles. The exceptions were specimens A1-1 and A2-1, which were only tested for five and four phases, respectively, because of problems with the displacement transducers at the tops of the walls.

\section{EXPERIMENTAL RESULTS}

\subsection{Load-drift diagrams}

The relationships between the applied load and the drift (ratio of top displacement to height) of the walls obtained from the previously described testing protocol are depicted in Fig. 4. The displacement was recorded by LVDT-0, as shown in Fig. 3(a). Because walls A1-1 and A2-2 had the same dimensions and reinforcement configurations, they should present similar hysteretic curves. That similarity was observed only in the elastic range; the curves were quite different in the inelastic range. It is observed that all the hysteretic curves present the same level of pinching and unloading stiffness. The hysteretic loops seem to be symmetric and stable for positive and negative cycles up to a drift of 0.005 , except for wall A2-1. The experimental results for wall A1-1 were used in this study to calibrate the parameters of the 
numerical model, and then those values were verified using the results for the other walls.

\subsection{Crack patterns and failure mode}

Table 4 lists the qualitative behaviors of the specimens in every phase during the tests. In summary, most of the specimens presented cracks at the backs of the tie-columns in phase 1. The origin of these initial cracks was the flexure effect on the confining elements. In phase 2, the cracks in the bottoms of the columns became more serious. The number of cracks in the tie-columns increased in phase 3 along the height of the confining element, and the first shear cracks on the panel appeared. The shear cracks propagated in phase 4 , and they were found almost everywhere along the diagonal of the wall in phase 5. Two of the walls presented spalling in part of the bricks, and one of them presented crushing in a corner. Figure 5 shows a schematic representation of the final states of the walls. The red fissures appeared when the walls were pushed (from right to left in the figures), and the blue fissures appeared when the walls were pulled in the opposite direction.

\section{EVALUATION OF STRUCTURAL CHARACTERISTICS}

\subsection{Maximum strength of walls}

The wall performance can be evaluated in terms of structural characteristics such as the strength, ductility, and energy absorption [7]. The maximum strengths can be estimated from the results of the experiments as the peak lateral loads from the hysteretic curves. A summary of these results is presented in Table 5. Figure 6(a) shows skeleton curves estimated from the experimental results for all the specimens. The behaviors of the walls in the elastic range are similar when the drift is smaller than approximately 0.0007 . The responses of the specimens in the inelastic range show slight variations. Specimens A1-2 and A2-2 present the largest maximum strengths. Specimen A2-1 exhibits the lowest value because the associated drift of this specimen was also the smallest.

\subsection{Initial stiffness and stiffness degradation}

In the design and evaluation of structures, it is important to assess the stiffness degradation with respect to the increment of the drift. This characteristic is usually helpful to define drift limits for design purposes (i.e., serviceability, collapse prevention, etc.). To estimate the initial stiffness before cracking, the expression presented below was used, which 
considers the case of a cantilever beam. In this equation, shear and flexural deformations can be considered.

$$
K=\frac{1}{\left(\frac{h_{w}^{3}}{3 E_{m} I}+\frac{h_{w}}{G_{m} A v}\right)}
$$

where $E_{m}$ is the elastic modulus of masonry, and $G_{m}$ is the shear modulus of masonry (defined as $0.40 E_{m}$ in [3]). These were assumed to follow the values listed in Table 2. $A v$ is the shear area, and $I$ is the moment of inertia of the transformed section, where the concrete sections of the tie-columns were converted to masonry considering the ratio of $E_{c}$ to $E_{m}$. Because all the walls have the same geometry and equivalent elasticity modulus, the initial stiffness for all the specimens is $151.64 \mathrm{kN} / \mathrm{mm}$.

The initial positive stiffness $\left(K_{i n i}{ }^{+}\right)$is defined by taking an average value of the two cycles in the first phase as the ratio between the force and the maximum positive horizontal displacement. The initial negative stiffness $\left(K_{i n i}{ }^{-}\right)$is defined for the negative part of a cycle in a similar manner (Fig. 6(b)). The initial equivalent stiffness $\left(K_{\text {ini-eq }}\right)$ is estimated as the slope between the peak positive and negative displacements for the first cycle in the first phase. Table 5 presents the initial stiffness obtained from the experimental results for the first phase. A discrepancy of less than $16 \%$ is observed between the theoretical value $\left(K_{\text {Theo }}\right)$ and that from the experimental results in the case of walls A1-1 and A2-1.

Table 6 lists the variations in the initial stiffnesses for the specimens of group A1. Because of the development of cracks, the equivalent initial stiffness decreases as the displacement increases. A similar tendency can be found in the specimens of group A2.

Figure 6(b) shows the variation in the lateral equivalent stiffness $\left(K_{e q}\right)$ with respect to the drift of the specimens. It can be observed that there are no significant differences between the curves of the first and second cycles for all the specimens. Although specimen A2-1 exhibits a reduction in the lateral equivalent stiffness, the results are rather similar among the four specimens. The lateral stiffnesses of all the walls showed significant reductions in the inelastic range. The lateral stiffness is less than $40 \%$ of its initial value for a drift of 0.00125 . When the specimens reached the drift limit (drift $=0.005)$ established by the Peruvian code [20], the lateral stiffness decreased to almost $15 \%$ of the initial value. This was produced by an increase in the width and depth of the cracks. The spalling of the masonry started when the drift was approximately 0.01 , where the specimens had a $93 \%$ reduction in the initial stiffness. 


\subsection{Dissipated energy and equivalent viscous damping}

A convenient approach for estimating the energy dissipated is to determine the area under the load-displacement diagrams [21]. Figure 6(c) shows the cumulative dissipated energy as a function of the drift. As can be seen, all the specimens exhibit almost the same amount of dissipated energy in every cycle. For the first two phases (drift smaller than 0.0006), a very small amount of energy was dissipated.

Another way to estimate energy dissipation is in terms of damping. In the case of structural elements subjected to cyclic loads, it is common to use the equivalent viscous damping $\left(\xi_{e q}\right)$ defined in Eq. (2) [21].

$$
\xi_{e q}=\frac{1}{4 \pi}\left(\frac{E_{D}}{E_{S 0}}\right)
$$

where $E_{D}$ is the dissipated energy in one cycle, and $E_{S O}$ is the elastic strain energy stored in an equivalent linear elastic system at the maximum displacement.

Because a hysteresis curve is not completely symmetrical, $\xi_{e q}$ was estimated in two ways: one with the positive part of the cycle $\left(\xi_{e q}{ }^{+}\right)$and the other with the negative part of the cycle $\left(\xi_{e q}{ }^{-}\right)$. Figure $6(\mathrm{~d})$ shows the equivalent viscous damping, which is derived using the positive part of the cycle, in terms of the drift. The equivalent viscous damping during the first two phases is approximately 0.05 for all the specimens. This value increases on average to 0.10 for a drift of 0.005 .

\subsection{Unloading stiffness}

Structures experience a reduction in stiffness as a function of the drift, as shown in section 4.2. This can be observed not only during the loading step, but also during the unloading step. Figure 6(e) shows the unloading stiffness with respect to the drift. There is some uncertainty in the unloading stiffness due to the non-linear response obtained in the hysteretic curves in Fig. 4. For this reason, the average unloading stiffness was estimated in the experiments. No significant variations are observed in the curves, similar to the loading stiffness. The unloading stiffness decreased to $40 \%$ of the initial value at a drift of 0.0013 , and it decreased to $15 \%$ of the initial value when the drift reached the limit specified by the standard [20].

\subsection{Summary of experimental results}

Comparing the structural characteristics estimated with respect to groups A1 and A2, the 
hysteretic curves obtained from the specimens have almost the same tendencies in terms of strength, stiffness degradation, dissipated energy, and equivalent viscous damping. Although the reinforcement of the confining elements was changed with respect to the two groups, similar response trends for all the walls were found. Despite these similarities in the trends of the evaluated structural characteristics, wall A1-1 presented a worse performance than the other walls. This may have been due to the problems during the construction process. Wall A1-1 was the only one that exhibited crushing of the corner. Note that only four phases were applied to wall A2-1 because of the problems with the transducers, which did not allow the maximum load of specimen A2-1 to be registered. Wall A2-1 showed inelastic responses under low loads relative to the other walls because of the lower reinforcement ratio in the tie-columns.

\section{CALIBRATION AND VALIDATION OF EQUIVALENT STRUT MODEL WITH SMOOTH HYSTERETIC MODEL USING GA}

The experimental program provided the responses of the typical CM walls that are used in low- and mid-rise dwellings in Peru. Numerical models of these walls are prepared and calibrated using the experimental results. These numerical models are prepared in the program IDARC 2D version 7 [22].

\subsection{Numerical modeling of walls}

The numerical modeling of masonry walls subjected to inplane loading allows the assessment of the behavior of this system to another excitation, without the need for more tests. It is known that the design criteria and construction techniques for CM walls and masonry infill walls are different, and the effect of the type of connection between the panel and confining elements has been studied [8, 13]. However, Torrisi et al. [14] established that the responses of these systems to inplane loads are somewhat similar, because the behavior of the system is controlled by the nonlinear response of the masonry wall panels and the surrounding RC elements. Consequently, these structural systems can be analyzed using similar models. According to [14], the experimental data and numerical simulations clearly indicate that a structural separation between the panel and the confining elements occurs at the initial stages in both cases (i.e., CM walls and infill walls). After the structural separation occurs, the formation of a diagonal compressive stress field in the masonry panel and the development of bending moments and shear and axial forces in the confining elements are 
observed.

There are many models to predict the behavior, strength, and stiffness of these systems. Some of these are empirical or semi-empirical, and others are sophisticated models to represent the geometry and material characteristics. These analytical models can be grouped into two categories: a) macro-models, which try to predict the behavior of the system as a whole and b) micro-models, which represent the mechanical properties of the materials to predict the behaviors in detail. Macro-models usually idealize the masonry panel as an equivalent strut model, which requires little computational effort. Micro-models usually use the solid mechanics to model the behaviors of the frames and panels. The finite element method (FEM) is widely used in this category, which requires a greater computational effort. Examples of these categories can be found in Marques and Lourenço [23] which used macro-element models to predict the capacity curve of masonry structures based on the pushover analysis and in Mohyeddin et al. [24] which employed FEM of RC frames with masonry infill panels to predict the behaviour of the infill-frame over a wide range of drift under in-plane and out-of-plane loading. In the present study, the first category was used. The masonry panels were represented as macro-models (i.e., compression strut elements with width $w$ in Fig. 7a) with a smooth hysteretic model for the two diagonals of the panel.

The IDARC 2D program assumes that the contribution of the masonry infill panel can be modeled by replacing the panel with two diagonal compression struts (Fig. 7(a)). Because the tensile strength of masonry is neglected, the individual masonry struts are considered to be ineffective in tension. The existence of the two diagonals struts provides lateral resistance to cyclic loading. The lateral force-deformation relationship for the structural masonry is assumed to be a smooth curve bounded by a linear strength envelope with an initial elastic stiffness until a yield force $V_{y}$, and there on a post-yield degraded stiffness until the maximum force $V_{m}$ is revealed (Fig. 7(b)).

The parameters used to define the behavior of the strut are the initial elastic stiffness of the panel $\left(K_{o}\right)$ and the lateral yield force of the panel $\left(V_{y}\right)$. In order to define $K_{o}$, we consider Eq. (3):

$$
K_{O}=E_{m} * A / L
$$

where $E_{m}$ is the modulus of elasticity of masonry, and $A$ and $L$ are the area and length of the equivalent strut, respectively. The area of the strut can be estimated as

$$
A=w^{*} t
$$

where $w$ is the width of the strut, and $t$ is the thickness of the wall. The definition of the width 
of the strut has been studied by many researchers $[25,26]$, but in the present study, the definition of Bazan and Meli [27] was employed. The effective width of the strut is defined as

$$
w=(0.35+0.022 * \lambda) * h
$$

where $h$ is the height of the story, and $\lambda$ is a dimensionless parameter based on the ratio of the relative stiffnesses of the panel and the frame, which is defined as

$$
\lambda=(E c * A c) /\left(G m^{*} A m\right)
$$

where $E_{c}$ is the modulus of elasticity of concrete, $A_{c}$ is the area of the tie-columns, $G_{m}$ is the shear modulus of masonry, and $A_{m}$ is the area of the wall. The value of $G_{m}$ can be considered to be $0.4 E_{m}$. Using the values presented in previous sections, the values of $\lambda$ and $w$ are estimated to be 4.68 and $104.19 \mathrm{~cm}$, respectively. Finally, the value of the stiffness of the panel is assumed to be $133.05 \mathrm{kN} / \mathrm{mm}$.

The yield force $V_{y}$ is defined according to the Peruvian design standard [2] as follows:

$$
V y=0.5(\alpha)\left(v^{\prime} m\right)(t)(L)+0.23\left(P_{g}\right)
$$

where $v^{\prime} m$ is the characteristic resistance to shear of masonry set in section $2.1, P_{g}$ is the service gravity load, $t$ is the thickness of the wall, and $L$ is the length of the wall, including the tie-columns. $\alpha$ is a reduction factor for shear due to the slenderness effects. The value of $\alpha$ is assumed to be one. By substituting the parameters, we obtain a value of $V_{y}$ equal to 153.87 $\mathrm{kN}$.

To model the confining elements, tie-column elements were considered as macro-elements with inelastic flexural deformations, and elastic shear and axial deformations. Bond beams elements were modeled using a nonlinear flexural stiffness model and linear elastic shear deformations. The hysteretic response of a section was traced using a three-parameter model that considered a trilinear polygonal skeleton, along with the stiffness degradation, strength deterioration, and pinching response.

Based on the damage observed in the test, most of the damage is concentrated in the masonry panel. For this reason, the selected values of the hysteretic parameter for confining elements were set to represent a moderate degrading of the elements: $\alpha=10, \beta_{1}=0.3, \beta_{2}=$ 0.15 , and $\gamma=0.25$, as proposed in [22].

The nonlinear behaviors of the concrete and reinforcement were considered as follows. In the case of concrete, confined concrete was assumed, and the Kent and Park model was employed in this study. The values of $f^{\prime} c$ and $E_{c}$ were assumed to follow those in section 2.1. 
The ultimate strain was set to 0.0035 , and the other parameters were estimated following the expressions of Kent and Park. The tensile strength of concrete was neglected.

The uniaxial behavior of the reinforcement was modeled using the trilinear model. The first part of this curve can be attributed to linear material behavior, for example, the stresses and strains are proportional to each other, whereas the second part is related to the inelastic incursion up to the limit stress. The last part of the model considers the hardening of the material. The yield strength $\left(f_{y}\right)$, yielding strain $\left(\varepsilon_{y}\right)$, maximum stress $\left(f_{u}\right)$, and hardening strain $\left(\varepsilon_{h}\right)$ were set as described in section 2.1 . The behaviors are considered to be the same for compressive and tensile stresses.

\subsection{Characteristics of hysteretic model}

Details about the hysteretic model can be found in [22], but they will be summarized in the next paragraphs, which principally show the parameters to be calibrated in the next sections.

The hysteretic model assumed in this study is based on the Sivaselvan and Reinhorn model [28]. This model is based on a smooth hysteretic force-displacement relationship, as follows:

$$
\begin{array}{r}
V_{i}=V_{y}\left[\alpha \mu_{i}+(1-\alpha) Z_{i}\right] \\
\mu_{i}=u_{i} / u_{y}
\end{array}
$$

where $V_{i}$ and $V_{y}$ are the instantaneous force and yield force, respectively; $\alpha$ is the ratio of post yielding stiffness to the initial stiffness; $\mu_{i}$ is the ductility at an arbitrary time; and $Z_{i}$ is the hysteretic component determined by Eq. (10):

$$
d Z_{i}=\left[A-\left|Z_{i}\right|^{n}\left(\beta \operatorname{sgn}\left(d \mu_{i} Z_{i}\right)+\gamma\right)\right] d \mu_{i}
$$

where $A, \beta$, and $\gamma$ are constants used to control the shape of the hysteretic loop. The signum function is equal to 1 in a case where the argument is higher than 0 and -1 in a case where the argument is lower than $0 . n$ is a parameter that controls the rate of transition from the elastic to yielded state.

The stiffness degradation is incorporated in the hysteretic model by including a parameter $\eta$ in Eq. 10 as follows:

$$
d Z_{i}=\frac{\left[A-\left|Z_{i}\right|^{n}\left(\beta \operatorname{sgn}\left(d \mu_{i} Z_{i}\right)+\gamma\right)\right]}{\eta} d \mu_{i}
$$


where $\eta$ is estimated as

$$
\eta=1+S_{k}\left(\frac{\mu_{\max }+\mu_{i}}{2}\right)
$$

where $S_{k}$ is a control parameter used to vary the rate of stiffness decay as a function of the current ductility $\mu_{i}$, as well as the maximum attained ductility $\mu_{\max }$, before the start of the current unloading or reloading cycle.

The strength degradation was modeled considering the reduction of the panel using Eq. (13), where the factor $s_{\beta}$ determines the amount of deterioration of the original yield force, as expressed by Eq. (14).

$$
s \beta=1-\left(\frac{\mu_{\max }-1}{\mu_{c}-1}\right)\left(\frac{1}{1-\left(\frac{S_{p 1} \int d E_{h}}{4 E_{h y}}\right)^{S} p 2}\right)
$$

where $\mu_{\max }$ is the maximum attained ductility in the response history, $\mu_{c}$ is the ductility capacity of the infill panel, parameters $S_{p 1}$ and $S_{p 2}$ control the rate of strength deterioration, $E_{h}$ represents the cyclic energy dissipated before the start of the current reloading cycle, and $E_{h y}$ is the monotonic energy capacity.

The effect of the pinching of the hysteretic loops considers the opening and closing of the cracks in the masonry panel. IDARC 2D considers the slip-lock element proposed by Baber and Noori [29]. The hysteretic parameter $Z$ will satisfy the following expression:

$$
\frac{d Z}{d \mu}=\frac{A-\left|Z_{i}\right|^{n}\left(\beta \operatorname{sgn}\left(d \mu_{i} Z_{i}\right)+\gamma\right)}{\eta\left[1+a \exp \left(-\frac{(Z-\bar{Z})^{2}}{\left(Z_{S}\right)^{2}}\right)\left[A-\left|Z_{i}\right|^{n}\left(\beta \operatorname{sgn}\left(d \mu_{i} Z_{i}\right)+\gamma\right)\right]\right]}
$$

where the parameter $Z_{s}$ controls the sharpness of the slip. Slip occurs in a range of $Z$ equal to $Z_{s}$, and it is symmetric about $Z=0$. In order to shift the effective slip region to be symmetric about an arbitrary $Z=\bar{Z}$, the value of $Z$ used for slip may be offset by a value $\bar{Z}$. The slip length $a$ is assumed to be a function of the attained ductility as follows:

$$
a=A_{S}\left(\mu^{r}-1\right)
$$


where $A_{s}$ is a control parameter used to vary the slip length, which may be linked to the size of the crack openings or reinforcement slip, and $\mu^{r}$ is the normalized displacement attained at the load reversal prior to the current loading or reloading cycle.

The necessary parameters for the hysteretic model are summarized in Table 7.

\subsection{Calibration process based on genetic algorithm}

A genetic algorithm (GA) is an optimization process inspired by Darwin's theory of evolution. This procedure is well known to optimize an objective function with linear or non-linear constraints [30], which makes it highly efficient at dealing with large, discrete, non-linear, and poorly understood optimization problems lacking a derivative evaluation of the error function. GA has recently been applied to the field of structural engineering, e.g., Wang and Ohmori [31] employed a layered GA in order to optimize the structural design of truss by taking into consideration their ultimate load-carrying capacity. Belevičius et al. [32] optimized the weight of tall guyed masts with stochastic GA, and Sengupta and Li [33] employed GA to calibrate an analytical model of hysteresis behavior for RC beam-column joints with limited transverse reinforcement. This method does not guarantee the optimum solution of the problem, but it does make it possible to identify a set of optimum solutions, which are close to the optimum solutions in a given space.

The current research uses a simple form of GA for the hysteretic parameter calibration. All of the GA techniques use the same steps: definition of a population, encoding, initial population, reproduction, crossing, mutation, generation of new populations, and testing of convergence.

In the definition of the population and encoding, each parameter of the hysteretic model is binary encoded (e.g., 11001) to represent a gene. The real parameter $X\left(x_{1}<X<x_{2}\right)$ can be calculated as

$$
X=x_{1}+\frac{B\left(x_{2}-x_{1}\right)}{2^{M}-1}
$$

where $x_{1}$ and $x_{2}$ are the lower and upper limits of the search space for the parameter $X, M$ is the length of the gene, and $B$ is the decimal value of the binary string. For example, when the string 101 and $x_{1}=0.5, x_{2}=1.5, M=3$ are considered, $B=1 \times 2^{0}+0 \times 2^{1}+1 \times 2^{2}=5$ and $X=$ 1.214 can be calculated. As a result of this discretization, the search space of every parameter is limited to discrete points within the range. In this study, we considered a five-bit long gene. The string 00000 corresponds to the lower bound, and 11111 corresponds to the upper bound 
for the binary codification. The union of several genes forms an individual. Each individual represents a point in the search space. The population is defined as a group of $\mathrm{N}_{\mathrm{i}}$ individuals in the $\mathrm{i}$-th generation.

The initial population $N_{0}$ is randomly generated in the search space. Then, the mechanisms of selection, reproduction, and mutation are employed to evolve the population to the best individuals in the search space.

In the selection mechanism, an error function for each individual of the population is evaluated. The individuals with lower error values should survive to produce offspring. Therefore, it is necessary to devise a fitness function so that parameter sets with better predictions result in lower fitness values. The error function defined by this study is presented in Eq. (18)

$$
\text { E.I. }=\left(\sum_{j=1}^{4} e_{j}\right) / 4
$$

where $e_{j}$ is the relative error of a structural characteristic based on the hysteretic curves (i.e., strength, stiffness degradation, cumulative dissipated energy, and unloading stiffness). The relative error of a structural characteristic is defined as

$$
e_{j}=\left(\frac{\sum_{k=1}^{r}\left(Y_{\text {test }}-Y_{\text {sim }}\right)^{2}}{\sum_{k=1}^{r} Y_{\text {test }}{ }^{2}}\right)^{1 / 2}
$$

where $Y_{\text {test }}$ is the structural characteristic obtained from the test, $Y_{\text {sim }}$ is the structural characteristic obtained from the numerical simulation, and $r$ is the number of referenced points of the structural characteristics. Depending on their fitness, only the best $\mathrm{N}_{\mathrm{i}} / 2$ individuals are preserved to generate the next population.

For the mechanism of reproduction and crossing, the parents are duplicated and then randomly paired while being careful not to match the same parents. Then, we cross over to generate new pairs of offspring by exchanging part of the genes of one parent with those of another. The locations of the crossover points are chosen randomly.

To limit the convergence problems and diversify the population, some offspring are randomly mutated by changing the code of one bit of one gene. The selections of the individual and the gene to be mutated are performed randomly. The probability of mutation is 
set to 0.005 . This is the final population, and is called a new population.

Finally, the error function is evaluated for the new population. The previous steps are repeated until the error function of the new generation is less than a given error or until a limited number of generations is reached. This process was repeated for five trials in this study. Table 7 lists the search space for every parameter. The ranges of values were determined based on the values presented by Reinhorn et al. [22].

Using the initial values presented in Table 7 (fourth column), the GA process was carried out, and the variations in the error function with respect to the number of generations were evaluated. A value of 20 was used for the number of individuals per generation. The smallest E.I. among these 20 individuals was regarded as the best solution in every generation. Figure 8 shows the variations in the smallest E.I. with the number of generations used in the analysis. As can be observed, an increase in the number of generations did not significantly affect the value of the smallest E.I. The number of individuals in every generation was changed from 20 to 50, but the differences in the obtained E.I. values were not large.

Then, the variations in the parameters with respect to the number of generations were evaluated (Fig. 9). It can be observed that parameter A tends to present a value between 0.75 and 1.1. Parameter $\alpha$ tends to have values larger than 0.03. Parameter As ranges from 0 to 0.2 . Parameter $S_{k}$ tends to be between 0.5 and 2. The other parameters did not show clear tendencies, except for $n$. It shows a value larger than 2.8. These findings led us to reallocate the search space of the parameters, as listed in Table 7 (fifth column), and a second analysis was performed. For parameters $A$ and $S_{k}$, the search space was narrowed, whereas the search space was extended for the other parameters.

In the second analysis, similar tendencies for parameters $A, \alpha, A s$, and $S_{k}$ were observed. However, a new range was found for parameter $n$. Figure 10 shows the variations in the parameters obtained in the second analysis. Parameter $n$ ranged between 2.5 and 5.5. Once again, the other parameters did not show clear tendencies, similar to the first analysis.

Based on these two analyses and [34], those parameters that did not present clear tendencies had little influence on the structural characteristics. Then, a third analysis was carried out, assuming constant values for these parameters, following those in reference [22]. New ranges of values were assigned for parameters such as $A, \alpha, A s$, and $S_{k}$, based on the previous analysis. The parameters considered in this third analysis are listed in Table 7 (sixth column). Figure 11 shows the variation of the smallest E.I. with respect to the number of generations in the second and third analyses. The error function of the third analysis shows a 
smaller value than that of the second analysis. Table 8 lists the parameters associated with the smallest E.I. for every trial. All of the estimated parameters presented a low coefficient of variation (C.V.), except for the parameter As.

Figure 12 compares the response from the numerical simulation using the estimated parameters with the experimental results of wall A1-1. The results of the numerical simulation show good agreement with those of the experiment in terms of the hysteretic curve, strength, stiffness degradation, cumulative dissipated energy dissipated, and unloading stiffness.

\subsection{Validation of parameters based on results for other walls}

A set of parameters that define a smooth hysteretic model used for masonry panels was calibrated using the results from the test of a typical wall, A1-1. The applicability of those parameters is evaluated using the results from other tests. The validation was performed by comparing the same structural characteristics presented in section 4 . The set of parameters used in the validation process included the mean value of each parameter presented in Table 8 .

Figure 13 shows a comparison between the hysteretic curves obtained from the numerical simulation and the test for the other three walls. As can be observed, the hysteretic curves obtained from the numerical simulation show good estimations of those obtained from the experimental results, especially for a drift smaller than 0.006 . The structural characteristics (i.e., strength, stiffness degradation, cumulative dissipated energy, and unloading stiffness) obtained from the hysteretic curves also show good correlations.

\section{SUMMARY AND CONCLUSIONS}

The results of static cyclic tests of four full-scale CM walls carried out at CISMID, UNI were presented. The parameters used to define a smooth hysteretic model for masonry panels were estimated and validated using the hysteretic curves and structural characteristics of the responses.

Although the specimens had different amounts of reinforcement in the confining elements, most of the curves showed similar tendencies in terms of the strength, stiffness degradation, energy dissipated, and equivalent viscous damping. This could indicate that the behavior of the specimens was mainly governed by the characteristics of the masonry panel. There was a slight reduction in the maximum strength and lateral stiffness when the lowest reinforcement ratios for the bond beams and tie-columns were used in the confining elements. In all the analyzed specimens, no clear strength degradation was observed. Among all the 
structural characteristics evaluated, the equivalent viscous damping exhibited more dispersion than the others. The mean value of the equivalent viscous damping was 0.05 for the first two phases. In the cracked state, the walls presented an equivalent viscous damping of 0.10 on average.

The hysteretic behavior of the panel was modeled considering 12 parameters. From the process of calibrating the numerical model using GA, it was found that parameters $A, n, \alpha, A s$, and $S_{k}$ presented mean values equal to $0.836,4.142,0.044,0.005$, and 1.145 , respectively. On the other hand, parameters $\beta, \gamma, Z, \bar{Z}, S_{p 1}, S_{p 2}$, and $\mu_{\max }$ did not show clear tendencies. Therefore, we infer that they had small influences on the structural characteristics, i.e., the strength, lateral stiffness, energy dissipated, and unloading stiffness.

Although only a limited number of specimens were tested to obtain their structural characteristics, the comparisons between the experimental data and the simulated results indicated good agreement in this research. However, additional experimental results are still required. The results validates the use of the proposed values for the model parameters in the case of CM walls. The model makes it possible to assess the behavior of existing structures, and the damage to these walls due to earthquakes will be investigated in a future study.

\section{ACKNOWLEDGMENTS}

The authors would like to express their sincere gratitude to the Japan Science and Technology Agency (JST) and Japan International Cooperation Agency (JICA) under the SATREPS project "Enhancement of earthquake and tsunami disaster mitigation technology in Peru" and to the anonymous reviewers who made valuable suggestions to increase the technical quality of the paper.

\section{REFERENCES}

[1] EERI: 2004, “Confined masonry construction,” World Housing Encyclopedia Report.

[2] SENCICO (2006). "Standard E.070 masonry,” National Building Regulations, Lima, Perú. (In Spanish).

[3] San Bartolomé A.; Quiun D. and Silva W. (2011) "Design and construction of masonry structures for earthquake resistance, " Fondo Editorial PUCP, Lima, Peru. (In Spanish).

[4] Decanini, L.D.; Payer, A.; Serrano, C. and Terzariol, R. (1985) "Experimental research on the seismic behavior of prototypes of masonry walls to natural scale," XXIII South American Conference on Structural Engineering. (In Spanish).

[5] Alcocer, S.M. and Zepeda, J.A. (1999). "Behavior of multi-perforated clay brick walls under 
earthquake-type loading," Proceedings of 8th North American Masonry Conference, Austin, Texas, USA. [6] Irimies, M.T. (2002) "Confined masonry walls: The influence of the tie-column vertical reinforcement ratio on the seismic behaviour," Proceedings of the 12th European Conference on Earthquake Engineering, London.

[7] Meli, R. (2003) "Behavior of masonry walls under lateral loads," Proceedings of the 5th World Conference on Earthquake Engineering, Rome, Paper 101a.

[8] Yoshimura, K.; Kikuchi, K.; Kuroki, M.; Nonaka, H.; Kim, K.T.; Matsumoto, Y. (2003) "Experimental study on reinforcing methods for confined masonry walls subjected to seismic forces," Proceedings of the 9th North American Masonry Conference, Clemson, pp. 89-100.

[9] Marinilli, A. and Castilla, E. (2004) "Experimental evaluation of confined masonry walls with several confining columns," Proceedings of 13th World Conference on Earthquake Engineering, Vancouver, B.C., Canada. Paper No 2129.

[10] Yañez, F.; Astroza, M.; Holmberg, A. and Ogaz, O. (2004) "Behavior of confined masonry shear walls with large openings," Proceedings of the 13th World Conference on Earthquake Engineering, Vancouver, B.C., Canada. Paper No 3438.

[11] Gouveia, J.P. and Lourenco, P.B. (2007) "Masonry shear walls subjected to cyclic loading: Influence of confinement and horizontal reinforcement," Proceedings of the 10th North American Masonry Conference, Missouri, pp. 838-848.

[12] Tena-Colunga, A.; Juárez-Ángeles, A. and Salinas-Vallejo, V. (2009) "Cyclic behavior of combined and confined masonry walls," Engineering Structures 31: pp. 240-259.

[13] Wijaya, W.; Kusumastuti, D.; Suarjana, M.; Rildova and Pribadi, K. (2011) "Experimental study on wall-frame connection of confined masonry wall," Procedia Engineering 14: pp. 2094-2102.

[14] Torrisi, G.S.; Crisafulli, F.J. and Pavese, A. (2012) "An innovative model for the in-plane nonlinear analysis of confined masonry and infilled frame structures," Proceedings of 15th World Conference on Earthquake Engineering, Lisboa, Portugal. Paper No 0574.

[15] Salinas, R.and Lazares, F. (2008) "Seismic performance of confined masonry buildings with tubular bricks in developing areas," Proceedings of 14th World Conference on Earthquake Engineering, Beijing, China. Paper No. 05-04-0003

[16] San Bartolome, A.; Quiun, D.; Barr K. and Pineda C. (2012) "Seismic reinforcement of confined masonry walls made with hollow bricks using wire meshes," Proceedings of 15th World Conference on Earthquake Engineering, Lisboa, Portugal. Paper No. 3211

[17] Zavala, C.; Honma, C.; Gibu, P.; Gallardo, J. and Huaco, G. (2004) "Construction, monitoring and improvement techniques for masonry housing CISMID/FIC/UNI,” Research Report. Japan-Peru Center for 
Earthquake Engineering Research and Disaster Mitigation. Lima, Peru (in Spanish).

[18] Alvarez, J.J. (1996) "Some topics on the seismic behaviour of confined masonry structures," Proceedings of 11th World Conference on Earthquake Engineering, Acapulco, Mexico. Paper No. 180.

[19] ININVI (1982) “Technical standard for building E-070 masonry,” Ministry of Housing, Lima, Peru. (In Spanish).

[20] SENCICO (2003). "Standard E.030 seismic design,” National Building Regulations, Lima, Perú. (In Spanish)

[21] Chopra, A. (2012) "Dynamic of structures - Theory and applications to earthquake engineering," Third Edition. Pearson Prentice Hall, New Jersey.

[22] Reinhorn, A.M.; Roh, H.; Sivaselvan, M.; Kunnath, S.K.; Valles, R.E.; Madan, A.; Li, C.; Lobo, R. and Park, Y.J. (2009) "IDARC2D version 7.0: A program for the inelastic damage analysis of structures," Technical Report MCEER-09-0006, State University of New York at Buffalo.

[23] Marques, R. and Lourenço, P. (2014) "Unreinforced and confined masonry buildings in seismic regions: Validation of macro-element models and cost analysis," Engineering Structures 64: pp. 52-67

[24] Mohyeddin, A.; Goldsworthy, H. and Gad, E. (2013) "FE modelling of RC frames with masonry infill panels under in-plane and out-of-plane loading," Engineering Structures 51: pp. 73-87

[25] Flanagan, R.; Bennett, R. and Barclay, G. (1999) "In-plane behavior of structural clay tile infilled frames,” Journal of Structural Engineering. ASCE 125(6): pp. 590-599.

[26] Paulay, T. and Priestly M.J.N. (1992) "Seismic design of reinforced concrete and masonry building," John Wiley and Sons Inc, New York.

[27] Bazan, M. and Meli, R. (2009) "Seismic design of buildings," Limusa Noriega Ed. Mexico. (In Spanish).

[28] Sivaselvan, M.V. and Reinhorn, A.M. (1999). "Hysteretic models for cyclic behavior of deteriorating inelastic structures," Technical Report NCEER-99-0018, National Center for Earthquake Engineering Research, Dept. of Civil, Structural and Environmental Engineering, University at Buffalo, The State University of New York, Buffalo, NY.

[29] Baber, T.T. and Noori, M.N. (1985) "Random vibration of degrading pinching systems," Journal of Engineering Mechanics 111(8): pp. 1010-1026.

[30] Haupt, R.L. and Haupt, S.E. (2004) "Practical genetic algorithms," Second Edition. Wiley, New York.

[31] Wang, H. and Ohmori, H. (2013) "Elasto-plastic analysis based truss optimization using Genetic Algorithm," Engineering Structures 50: pp. 1-12.

[32] Belevičius, R.; Jatulis, D. and Šešoka D. (2013) "Optimization of tall guyed masts using genetic algorithms,” Engineering Structures 56: pp. 239-245. 
[33] Sengupta, P. and Li, B. (2013) "Modified Bouc-Wen model for hysteresis behavior of RC beam-column joints with limited transverse reinforcement," Engineering Structures 46: pp. 392-406

[34] Levasseur, S.; Malecot, Y.; Boulon, M. and Flavigny, E. (2007) "Soil parameter identification using a genetic algorithm," International Journal for Numerical and Analytical Method in Geomechanics 32: pp. 189-213. 


\section{CAPTIONS}

Table 1. Dimensions and reinforcements of walls and confining elements.

Table 2. Experimental results for masonry prism.

Table 3. Loading history for walls.

Table 4. Progression of cracking in specimens during experiments.

Table 5. Summary of properties of walls: maximum strengths $\left(\mathrm{F}_{\max }\right)$, estimation of initial stiffness $\left(\mathrm{K}_{\text {ini-eq }}\right)$, and theoretical initial stiffness $\left(\mathrm{K}_{\text {Theo. }}\right)$.

Table 6. Initial stiffnesses of specimens of group A1.

Table 7. Parameters for defining hysteretic behavior of masonry panels and search space used in genetic algorithm.

Table 8. Best solutions of parameters and associated relative errors and error function obtained by third analysis.

Fig. 1. a) General geometry of specimens and b) reinforcement of confining elements in specimen A1-1.

Fig. 2. Axial compression test prism used to determine $\mathrm{f}_{\mathrm{m}}$ and $\mathrm{E}_{\mathrm{m}}$.

Fig. 3. (a) Instrumentation of LVDTs and (b) load frame of CM walls.

Fig. 4. Overall hysteretic responses of walls: (a) A1-1, (b) A1-2, (c) A2-1, and (d) A2-2.

Fig. 5. Schematic figures of final states of walls: a) A1-1, b) A1-2, c) A2-1 (phase 4), and d) A2-2 [17].

Fig. 6. Structural characteristics: (a) skeleton curves, (b) lateral equivalent stiffness, (c) cumulative dissipated energy, (d) equivalent viscous damping, and (e) unloading stiffness with respect to drift of walls.

Fig. 7. (a) Equivalent strut model for masonry panels and (b) Strength envelope for masonry panels [22].

Fig. 8. Influence of number of generations on smallest E.I. values.

Fig. 9. Variations in values of parameters with respect to number of generations (first analysis).

Fig. 10. Variations in values of parameters with respect to number of generations (second analysis).

Fig. 11. Variations in smallest E.I. with respect to number of generations for (a) second analysis and (b) third analysis.

Fig. 12. Comparisons of experimental results with those of numerical simulation for wall A1-1: (a) hysteresis curves, (b) strength, (c) stiffness degradation, (d) cumulative dissipated energy, and (e) unloading stiffness.

Fig. 13. Comparison of simulated and experimental hysteretic curves for walls: a) A1-2, c) A2-1, and c) A2-2. 
Table 1. Dimensions and reinforcements of walls and confining elements.

\begin{tabular}{|c|c|c|c|c|c|c|c|c|c|}
\hline \multirow[b]{2}{*}{ Specimen } & \multicolumn{3}{|c|}{ Masonry } & \multicolumn{3}{|c|}{ Tie-column } & \multicolumn{3}{|c|}{ Bond beam } \\
\hline & $\begin{array}{c}\mathrm{L} \\
(\mathrm{mm})\end{array}$ & $\begin{array}{c}\mathrm{t} \\
(\mathrm{mm})\end{array}$ & $\begin{array}{c}\mathrm{H} \\
(\mathrm{mm})\end{array}$ & $\begin{array}{c}\mathrm{t} \\
(\mathrm{mm})\end{array}$ & $\begin{array}{c}\mathrm{b} \\
(\mathrm{mm})\end{array}$ & $\begin{array}{l}\text { Longitudinal } \\
\text { Reinforcement }\end{array}$ & $\begin{array}{c}\mathrm{h} \\
(\mathrm{mm})\end{array}$ & $\begin{array}{c}\mathrm{b} \\
(\mathrm{mm})\end{array}$ & $\begin{array}{l}\text { Longitudinal } \\
\text { Reinforcement }\end{array}$ \\
\hline A1-1 & \multirow{4}{*}{2650} & \multirow{4}{*}{205} & \multirow{4}{*}{2200} & \multirow{4}{*}{230} & \multirow{4}{*}{300} & $4 \# 4^{a}$ & \multirow{4}{*}{200} & \multirow{4}{*}{300} & $4 \# 3$ \\
\hline A $1-2$ & & & & & & 4 \#4 & & & $4 \# 4$ \\
\hline A2-1 & & & & & & $4 \# 3^{b}$ & & & $4 \# 3$ \\
\hline A2-2 & & & & & & $4 \# 4$ & & & $4 \# 3$ \\
\hline
\end{tabular}

a 4 \#4: Four conventional rebars, $12.7 \mathrm{~mm}$ in diameter, in the section of the element.

${ }^{\mathrm{b}} 4$ \#3: Four conventional rebars, $9.5 \mathrm{~mm}$ in diameter, in the section of the element. 
Table 2. Experimental results for masonry prism.

\begin{tabular}{lccccc}
\hline \multirow{2}{*}{ Type of brick } & Specimen & $\begin{array}{c}\text { Load }_{\text {max }} \\
\mathrm{kN}\end{array}$ & $\begin{array}{c}\text { Area } \\
\mathrm{mm}^{2}\end{array}$ & $\begin{array}{c}\text { Stress } \\
\mathrm{MPa}\end{array}$ & $\begin{array}{c}\mathrm{f}_{\mathrm{m}}^{\prime} \\
\mathrm{MPa}\end{array}$ \\
\hline \multirow{4}{*}{ Handmade } & $\mathrm{M} 1$ & 93 & 23,805 & 3.91 & \\
& $\mathrm{M} 2$ & 93 & 25,320 & 3.67 & \\
& $\mathrm{M} 3$ & 130 & 22,800 & 5.68 & 3.74 \\
& M4 & 130 & 23,575 & 5.50 & \\
& M5 & 102 & 22,800 & 4.46 & \\
\hline
\end{tabular}


Table 3. Loading history for walls.

\begin{tabular}{cccc}
\hline Phase & $\begin{array}{c}\text { No. of } \\
\text { Cycles }\end{array}$ & Drift & $\begin{array}{c}\Delta_{\mathrm{TOP}}{ }^{1} \\
(\mathrm{~mm})\end{array}$ \\
\hline 1 & 2 & $1 / 3200$ & 0.75 \\
2 & 2 & $1 / 1600$ & 1.5 \\
3 & 2 & $1 / 800$ & 3 \\
4 & 2 & $1 / 400$ & 6 \\
5 & 2 & $1 / 200$ & 12 \\
6 & 2 & $1 / 100$ & 24 \\
\hline
\end{tabular}

${ }^{1}$ Target displacement at the top of wall in every phase. 
Table 4. Progression of cracking in specimens during experiments.

\begin{tabular}{|c|c|c|c|c|}
\hline \multirow{2}{*}{ Phase } & \multicolumn{2}{|c|}{ Group A1 } & \multicolumn{2}{|c|}{ Group A2 } \\
\hline & A1-1 & A1-2 & A2-1 & A2-2 \\
\hline 1 & $\begin{array}{l}\text { Cracks on the back } \\
\text { of tie-columns }\end{array}$ & $\begin{array}{l}\text { Cracks on the back } \\
\text { of tie-columns }\end{array}$ & (No observation) & (No observation) \\
\hline 2 & $\begin{array}{l}\text { Cracks on the bottom } \\
\text { of the tie-columns }\end{array}$ & $\begin{array}{l}\text { Cracks on the bottom } \\
\text { of the tie-columns }\end{array}$ & $\begin{array}{l}\text { Cracks on the bottom } \\
\text { of the tie-columns and wall }\end{array}$ & $\begin{array}{l}\text { Cracks on the bottom } \\
\text { of the tie-columns and wall }\end{array}$ \\
\hline 3 & $\begin{array}{c}\text { Cracks in the middle of the } \\
\text { tie-columns and first shear cracks on } \\
\text { wall }\end{array}$ & $\begin{array}{l}\text { Cracks along the tie-columns } \\
\text { and first shear cracks on wall }\end{array}$ & $\begin{array}{l}\text { Cracks in the middle of the } \\
\text { tie-columns and first shear cracks } \\
\text { on wall }\end{array}$ & $\begin{array}{l}\text { Cracks in the middle of the } \\
\text { tie-columns and first shear cracks } \\
\text { on wall }\end{array}$ \\
\hline 4 & $\begin{array}{l}\text { Diagonal propagation } \\
\text { of shear cracks }\end{array}$ & $\begin{array}{l}\text { Diagonal propagation } \\
\text { of shear cracks }\end{array}$ & $\begin{array}{l}\text { Diagonal propagation } \\
\text { of shear cracks }\end{array}$ & $\begin{array}{l}\text { Diagonal propagation } \\
\text { of shear cracks }\end{array}$ \\
\hline 5 & $\begin{array}{l}\text { Diagonal cracks } \\
\text { all along the wall }\end{array}$ & $\begin{array}{l}\text { Diagonal cracks } \\
\text { all along the wall }\end{array}$ & - & $\begin{array}{l}\text { Diagonal cracks } \\
\text { all along the wall }\end{array}$ \\
\hline 6 & $\left(_{\text {Crushing of corner })^{a}}^{a}\right.$ & $\begin{array}{l}\text { Spalling of part of brick } \\
\text { from the central part of the wall }\end{array}$ & - & $\begin{array}{c}\text { Spalling of part of brick } \\
\text { from the central part of the wall }\end{array}$ \\
\hline
\end{tabular}

${ }^{\mathrm{a}}$ Observed damage pattern without recording of hysteretic curve at this phase. 
Table 5. Summary of properties of walls: maximum strengths $\left(F_{\max }\right)$, estimation of initial stiffness $\left(\mathrm{K}_{\text {ini-eq }}\right)$, and theoretical initial stiffness $\left(\mathrm{K}_{\text {Theo. }}\right)$.

\begin{tabular}{ccccccccc}
\hline Group Specimen & $\begin{array}{c}\mathrm{F}_{\max }{ }^{+} \\
(\mathrm{kN})\end{array}$ & $\begin{array}{c}\mathrm{F}_{\max }{ }^{-} \\
(\mathrm{kN})\end{array}$ & $\begin{array}{c}\mathrm{K}_{\text {ini }}{ }^{+} \\
(\mathrm{kN} / \mathrm{mm})\end{array}$ & $\begin{array}{c}\mathrm{K}_{\text {ini }}{ }^{-} \\
(\mathrm{kN} / \mathrm{mm})\end{array}$ & $\begin{array}{c}\mathrm{K}_{\text {ini-eq }} \\
(\mathrm{kN} / \mathrm{mm})\end{array}$ & $\begin{array}{c}\mathrm{K}_{\text {Theo. }} \\
(\mathrm{kN} / \mathrm{mm})\end{array}$ & $\mathrm{K}_{\text {ini-eq }} / \mathrm{K}_{\text {Theo. }}$ \\
\hline \multirow{2}{*}{1} & A1-1 & 230 & 209 & 129 & 125 & 127 & & 0.84 \\
& A1-2 & 247 & 256 & 138 & 160 & 149 & & 0.98 \\
\multirow{2}{*}{2} & A2-1 & 177 & 180 & 126 & 129 & 127 & & 0.84 \\
& A2-2 & 257 & 227 & 153 & 143 & 148 & & 0.98 \\
\hline
\end{tabular}


Table 6. Initial stiffnesses of specimens of group A1.

\begin{tabular}{|c|c|c|c|c|c|c|c|}
\hline \multirow{3}{*}{ Phase } & \multirow{3}{*}{ Cycle } & \multicolumn{3}{|c|}{ A1-1 } & \multicolumn{3}{|c|}{ A1-2 } \\
\hline & & $\mathrm{K}_{\mathrm{ini}}^{+}$ & $\mathrm{K}_{\text {ini }}^{-}$ & $\mathrm{K}_{\text {ini-eq }}$ & $\mathrm{K}_{\mathrm{ini}}{ }^{+}$ & $\mathrm{K}_{\text {ini }}^{-}$ & $\mathrm{K}_{\text {ini-eq }}$ \\
\hline & & $(\mathrm{kN} / \mathrm{mm})$ & $(\mathrm{kN} / \mathrm{mm})$ & $(\mathrm{kN} / \mathrm{mm})$ & $(\mathrm{kN} / \mathrm{mm})$ & $(\mathrm{kN} / \mathrm{mm})$ & $(\mathrm{kN} / \mathrm{mm})$ \\
\hline \multirow[t]{2}{*}{1} & 1 & 132.23 & 124.99 & 128.63 & 141.20 & 160.64 & 150.34 \\
\hline & 2 & 126.05 & 125.35 & 125.72 & 135.25 & 160.18 & 147.49 \\
\hline \multirow[t]{2}{*}{2} & 1 & 97.01 & 106.71 & 101.46 & 110.07 & 126.01 & 117.86 \\
\hline & 2 & 91.28 & 102.61 & 96.56 & 105.28 & 114.98 & 110.17 \\
\hline
\end{tabular}


Table 7. Parameters for defining hysteretic behavior of masonry panels and search space used in genetic algorithm

\begin{tabular}{|c|c|c|c|c|c|}
\hline \multirow{2}{*}{ Effect } & \multirow{2}{*}{ Parameter } & \multirow{2}{*}{ Definition } & \multicolumn{3}{|c|}{ Range of search space } \\
\hline & & & $1^{\text {st }}$ analysis & $2^{\text {nd }}$ analysis & $3^{\text {rd }}$ analysis \\
\hline Smooth hysteretic & $A$ & Parameter of hysteretic model & {$[0.5-1.5]$} & {$[0.75-1.1]$} & {$[0.75-0.9]$} \\
\hline \multirow[t]{4}{*}{ model } & $\beta$ & Parameter of hysteretic model & {$[0.001-0.6]$} & [0.001-1.2] & 0.1 \\
\hline & $\gamma$ & Parameter of hysteretic model & {$[0.5-1.6]$} & {$[0-2.2]$} & 0.9 \\
\hline & $n$ & Parameter of hysteretic model & {$[2-4]$} & {$[0-6]$} & {$[2-6]$} \\
\hline & $\alpha$ & Post yielding stiffness ratio & {$[0.01-0.05]$} & {$[0.03-0.07]$} & [0.04-0.065] \\
\hline Stiffness degradation & $S_{k}$ & Control parameter to vary the rate of stiffness decay & {$[0.1-5]$} & {$[0.1-2.5]$} & {$[0.5-1.5]$} \\
\hline \multirow[t]{3}{*}{ Strength degradation } & $S_{p 1}$ & Parameter to control the rate of & {$[0.001-1.6]$} & {$[0.001-3.2]$} & 0.8 \\
\hline & $S_{p 2}$ & strength deterioration & {$[0.5-1.5]$} & {$[0.001-3]$} & 1 \\
\hline & $\mu_{\max }$ & Ductility capacity of the infill panel & [45-55] & {$[30-70]$} & 50 \\
\hline \multirow[t]{3}{*}{ Slip-lock model } & As & Control parameter for slip length & {$[0.015-0.4]$} & {$[0-0.8]$} & {$[0-0.4]$} \\
\hline & $Z$ & Parameter that controls the sharpness of the slip & {$[0.01-0.5]$} & {$[0.01-1]$} & 0.1 \\
\hline & $\bar{Z}$ & Offset value for slip response & {$[-0.1-0.3]$} & {$[-0.3-0.6]$} & 0 \\
\hline
\end{tabular}


Table 8. Best solutions of parameters and associated relative errors and error function obtained by third analysis.

\begin{tabular}{|c|c|c|c|c|c|c|c|c|c|c|}
\hline \multirow{2}{*}{ Trial } & \multicolumn{5}{|c|}{ Parameters } & \multicolumn{5}{|c|}{ Relative errors and error function } \\
\hline & $\mathrm{A}$ & $\mathrm{n}$ & $\alpha$ & As & $\mathrm{S}_{\mathrm{k}}$ & $e_{\text {strength }}$ & $e_{\text {stiffness }}$ & $e_{\text {energy }}$ & $e_{\text {unlstiff }}$ & E.I. \\
\hline 1 & 0.842 & 4.065 & 0.045 & 0.000 & 1.177 & 0.060 & 0.031 & 0.065 & 0.108 & 0.066 \\
\hline 2 & 0.794 & 3.548 & 0.046 & 0.000 & 1.145 & 0.052 & 0.059 & 0.062 & 0.093 & 0.067 \\
\hline 3 & 0.866 & 4.452 & 0.044 & 0.013 & 1.113 & 0.067 & 0.035 & 0.063 & 0.126 & 0.073 \\
\hline 4 & 0.842 & 4.194 & 0.046 & 0.000 & 1.210 & 0.060 & 0.031 & 0.065 & 0.103 & 0.065 \\
\hline 5 & 0.837 & 4.452 & 0.042 & 0.013 & 1.081 & 0.056 & 0.030 & 0.061 & 0.109 & 0.064 \\
\hline Mean & 0.836 & 4.142 & 0.044 & 0.005 & 1.145 & & & & & \\
\hline C.V. $(\%)$ & 3.154 & 8.975 & 3.770 & 136.931 & 4.454 & & & & & \\
\hline
\end{tabular}




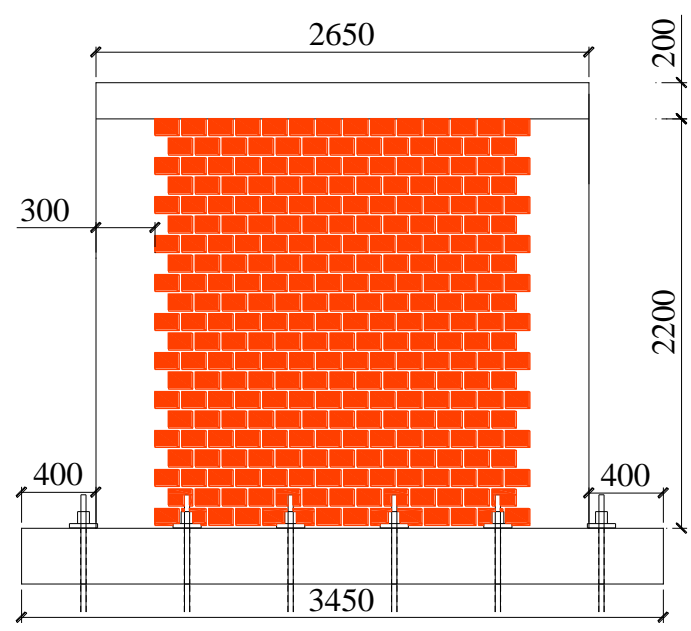

(a)

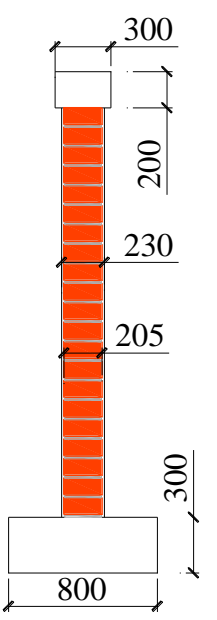

(b)

Fig. 1. a) General geometry of specimens and b) reinforcement of confining elements in specimen A1-1. 


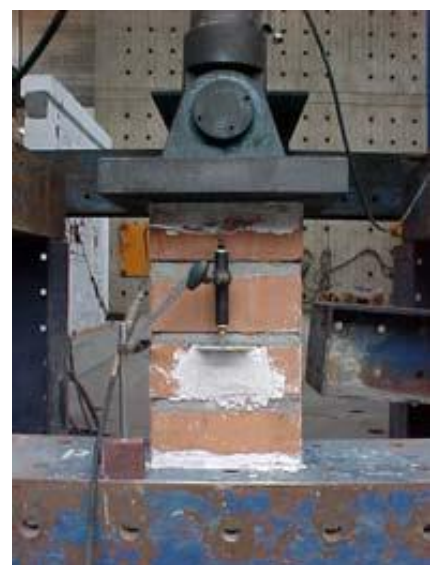

Fig. 2. Axial compression test prism used to determine $\mathrm{f}_{\mathrm{m}}$ and $\mathrm{E}_{\mathrm{m}}$. 


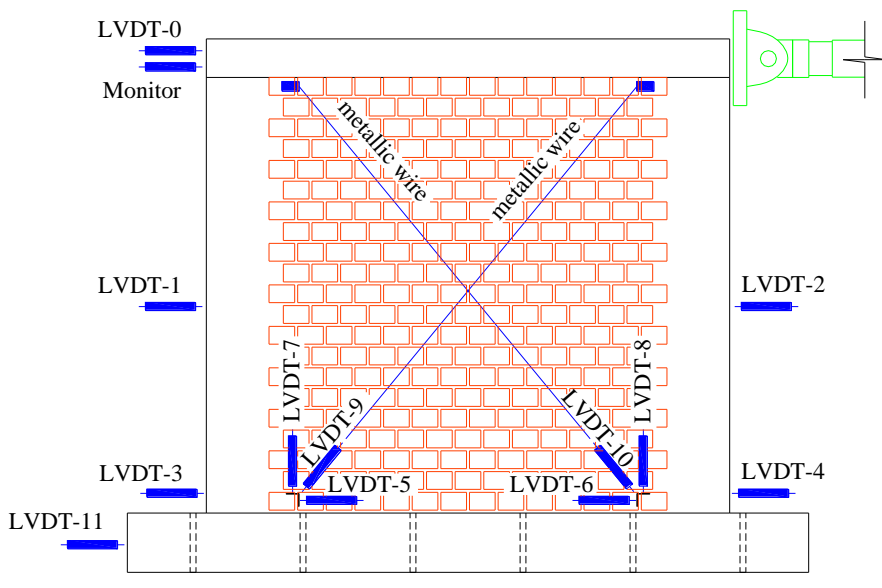

(a)

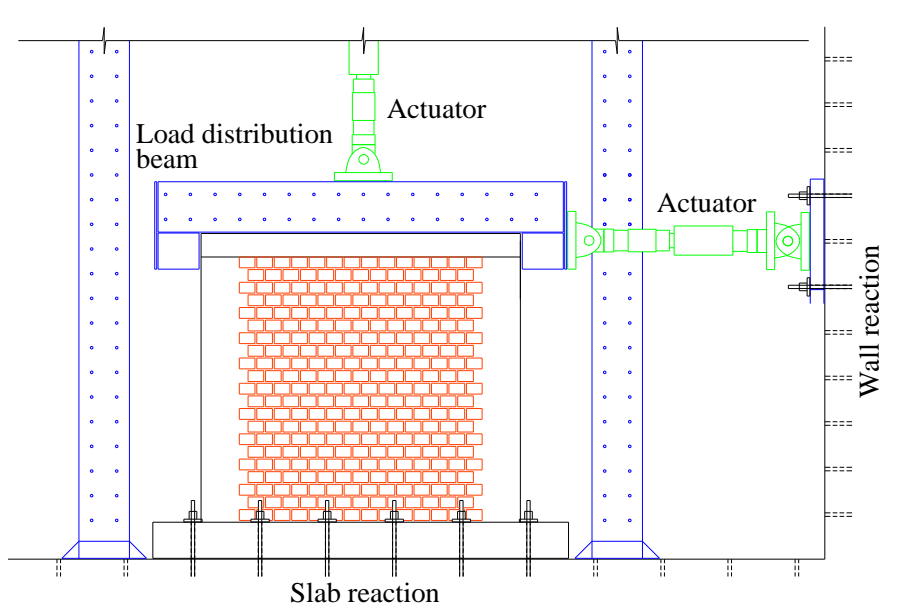

(b)

Fig. 3. (a) Instrumentation of LVDTs and (b) load frame of CM walls. 


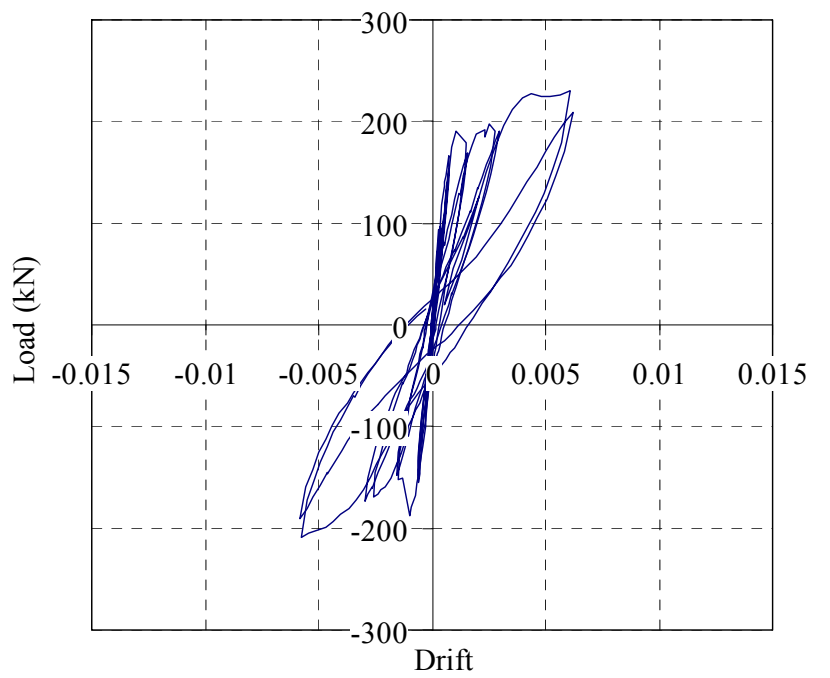

(a)

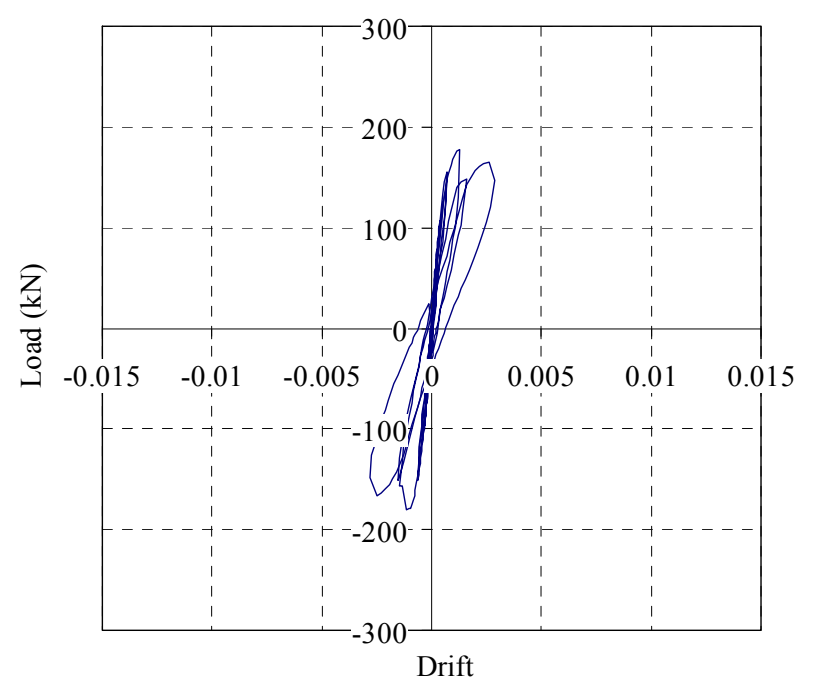

(c)

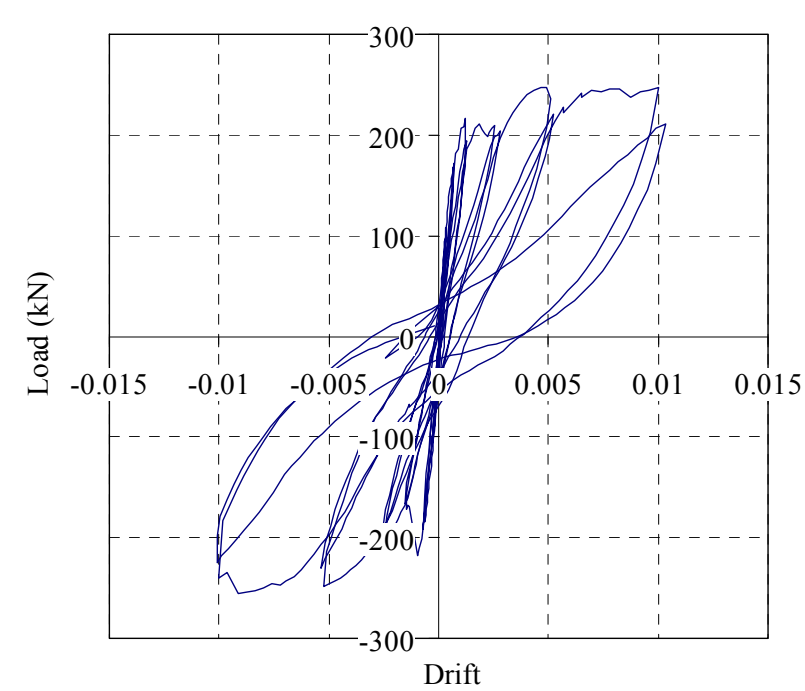

(b)

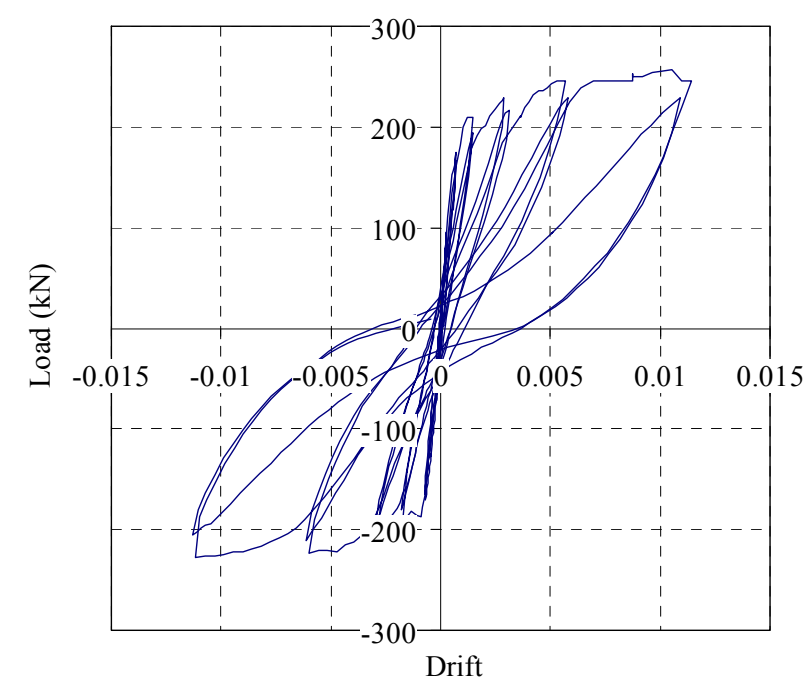

(d)

Fig. 4. Overall hysteretic responses of walls: (a) A1-1, (b) A1-2, (c) A2-1, and (d) A2-2. 


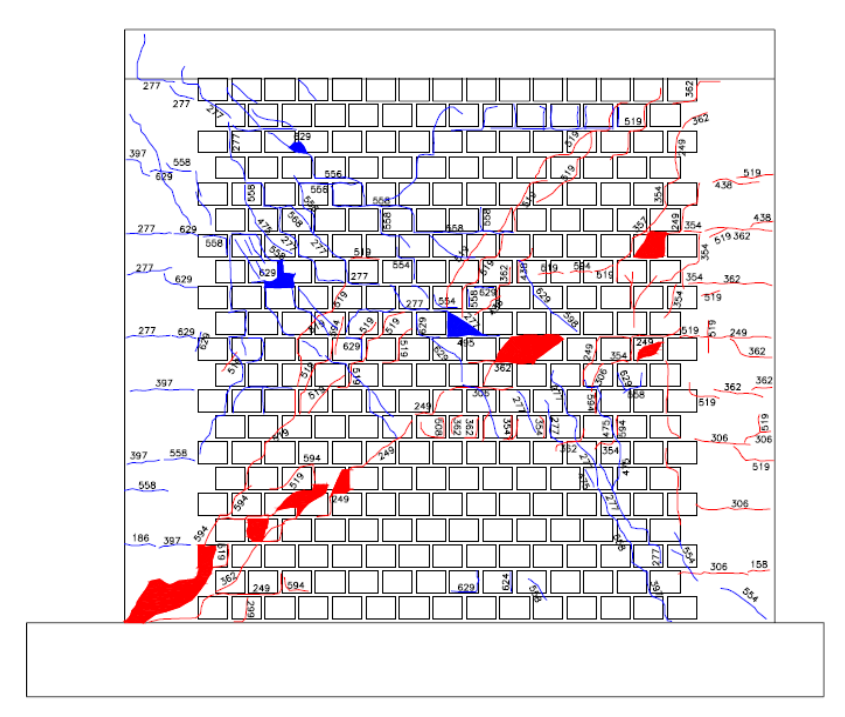

(a)

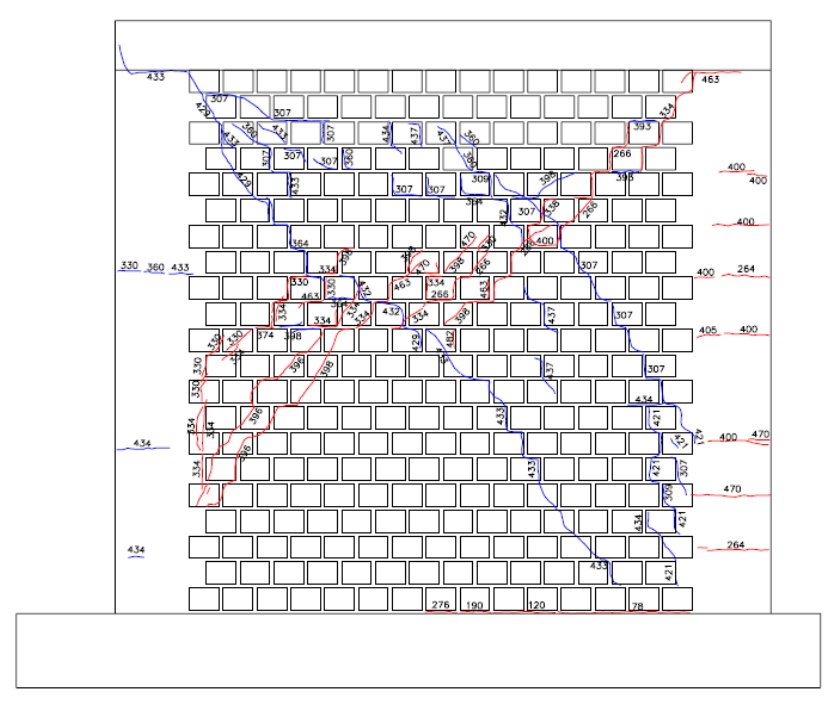

(c)

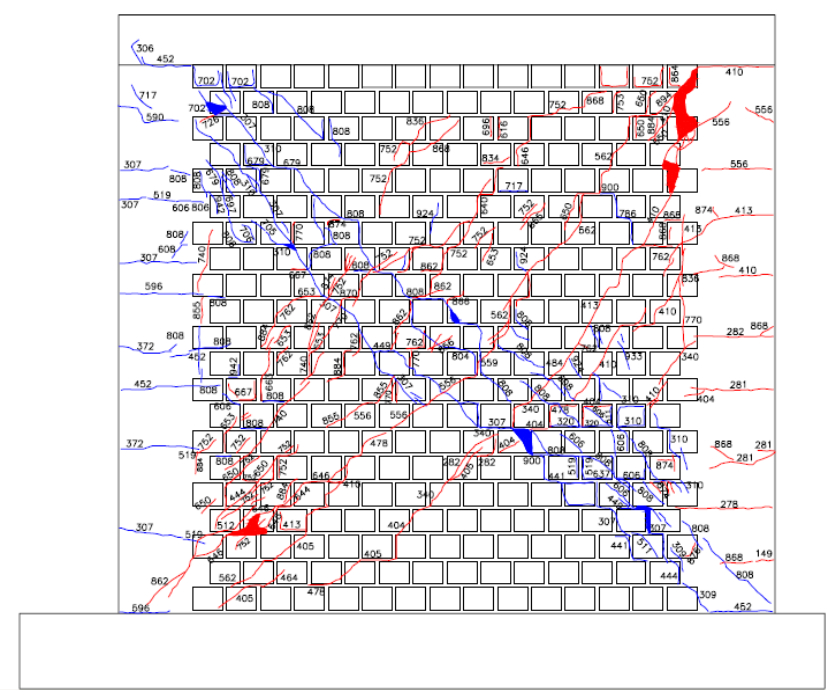

(b)

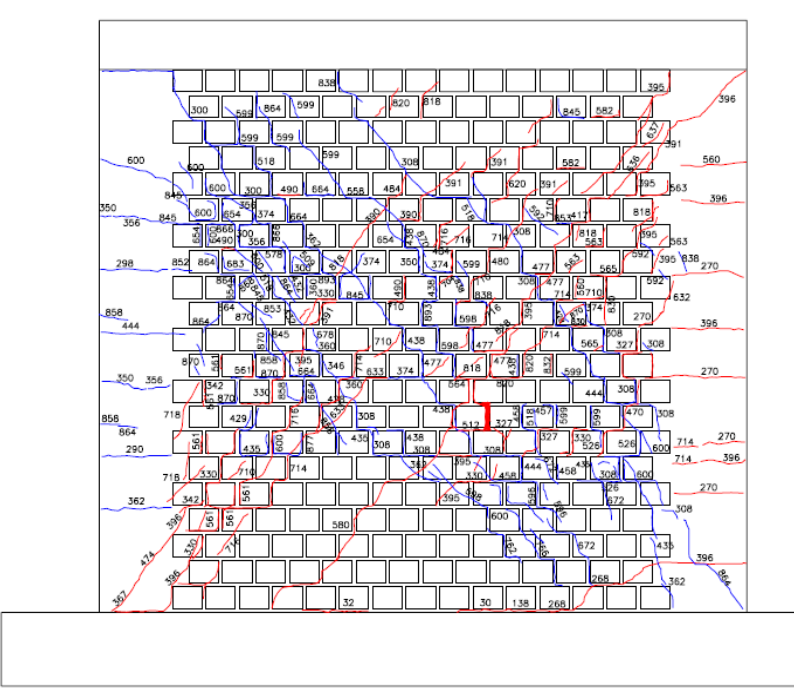

(d)

Fig. 5. Schematic figures of final states of walls: a) A1-1, b) A1-2, c) A2-1 (phase 4), and d) A2-2 [17]. 


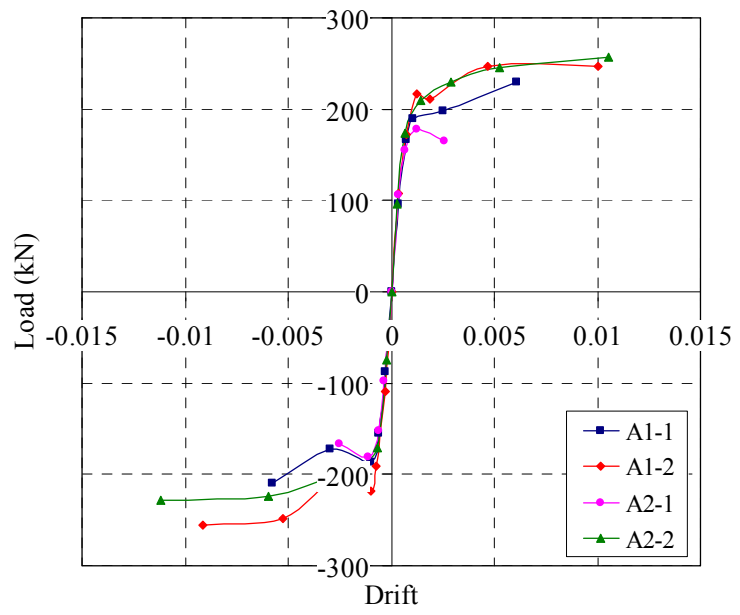

(a)
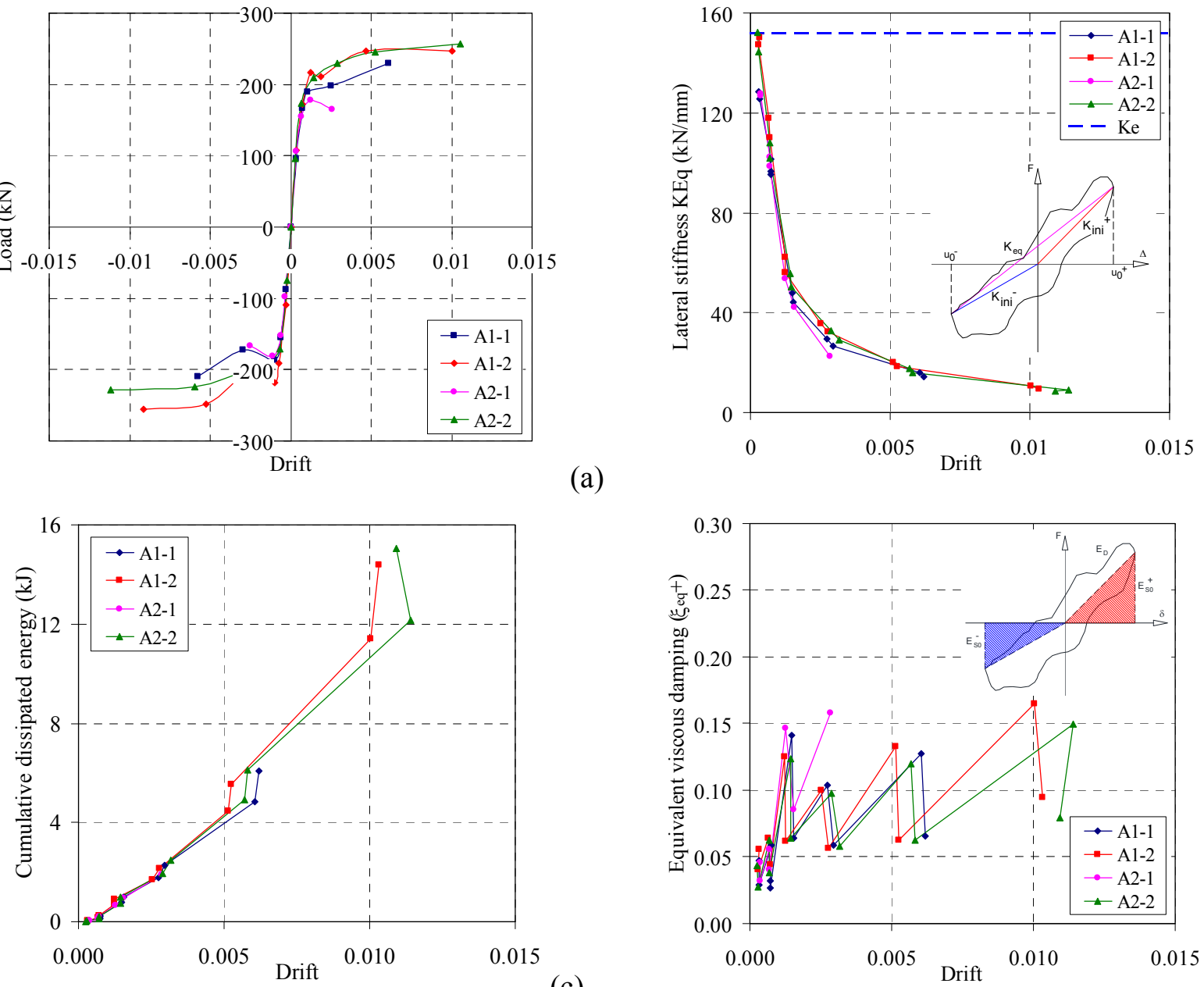

(b)

(c)

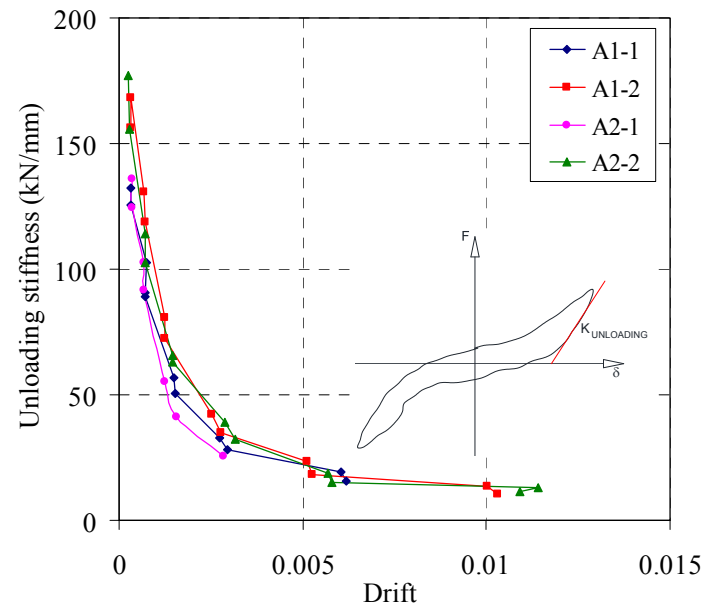

(e)

Fig. 6. Structural characteristics: (a) skeleton curves, (b) lateral equivalent stiffness, (c) cumulative dissipated energy, (d) equivalent viscous damping, and (e) unloading stiffness with respect to drift of walls. 


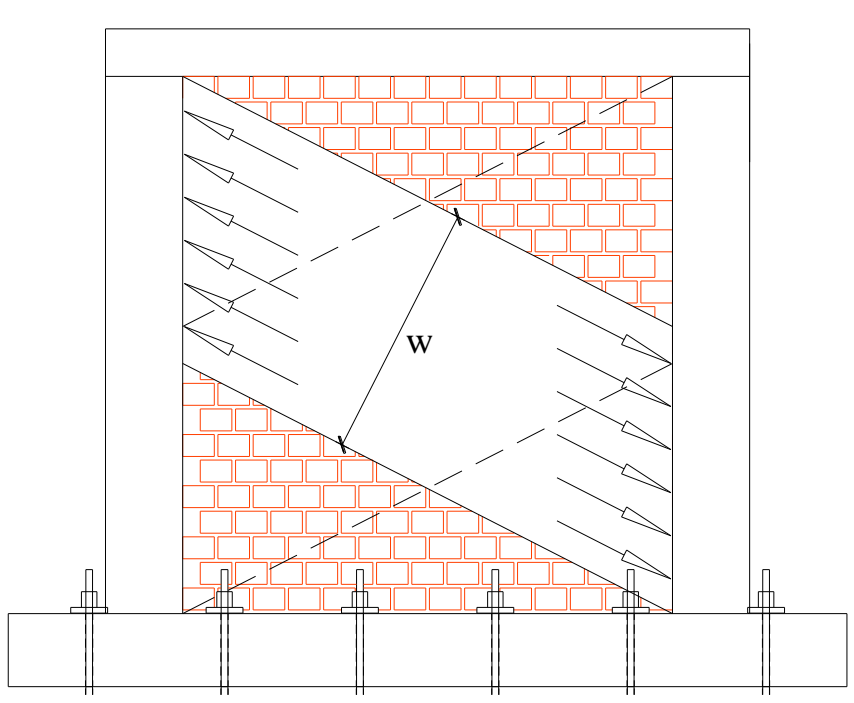

(a)

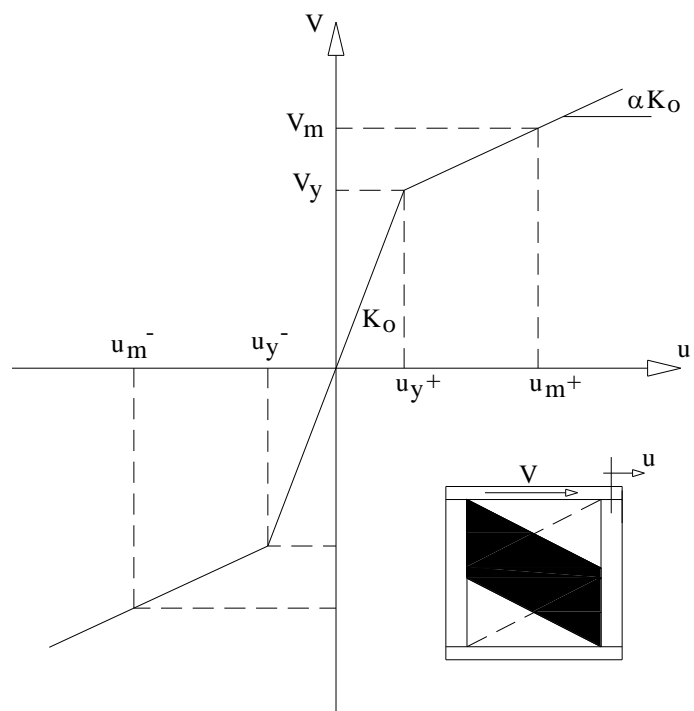

(b)

Fig. 7. (a) Equivalent strut model for masonry panels and (b) Strength envelope for masonry panels [22]. 

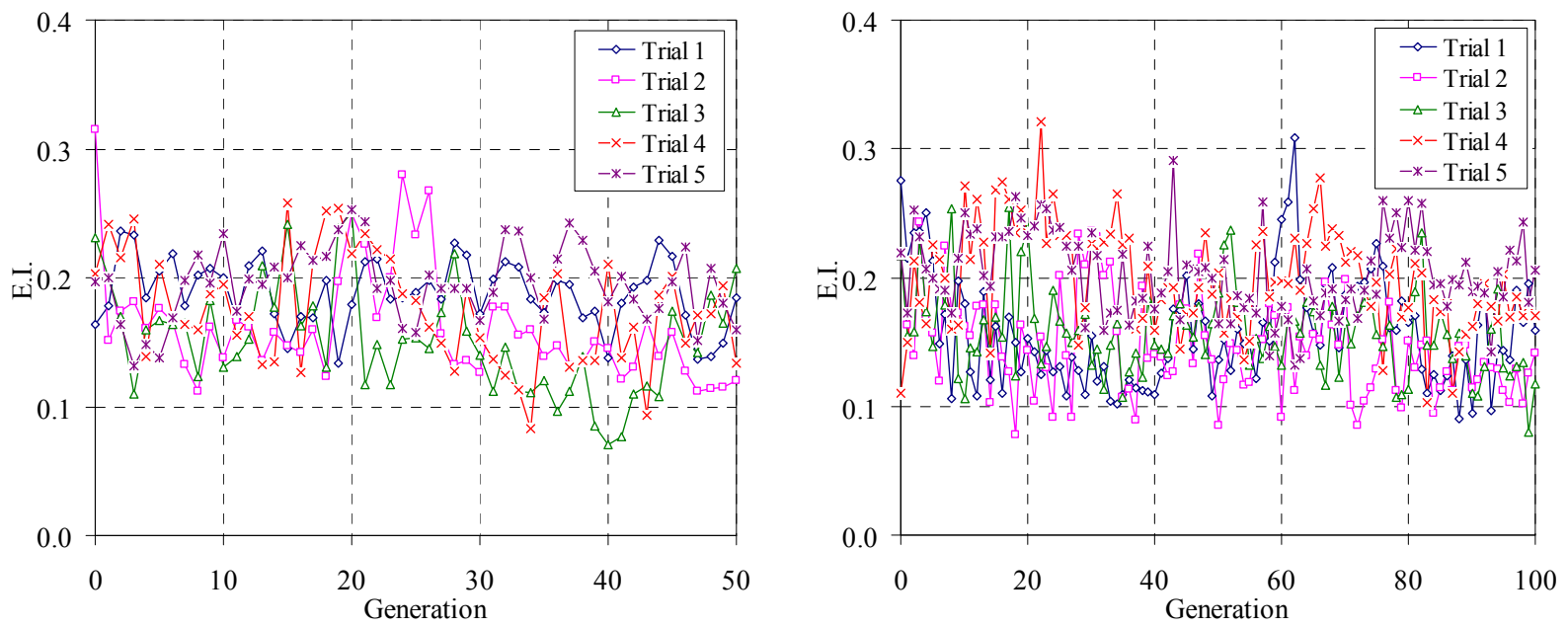

Fig. 8. Influence of number of generations on smallest E.I. values. 

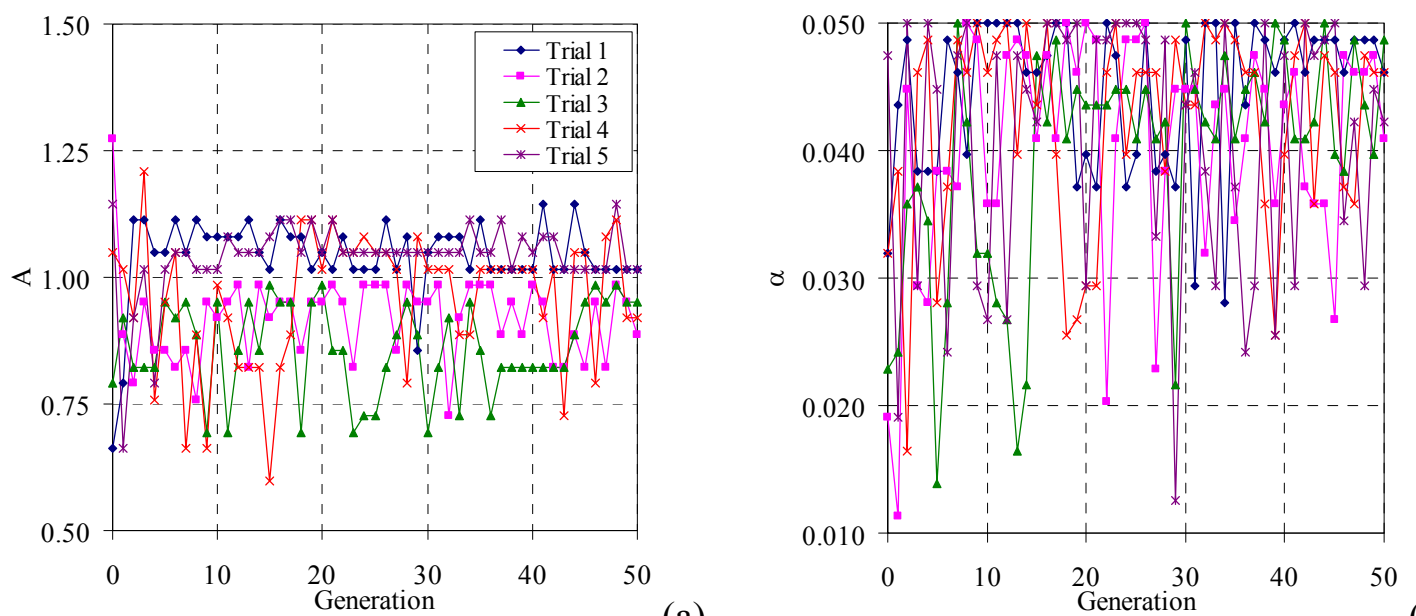

(a)
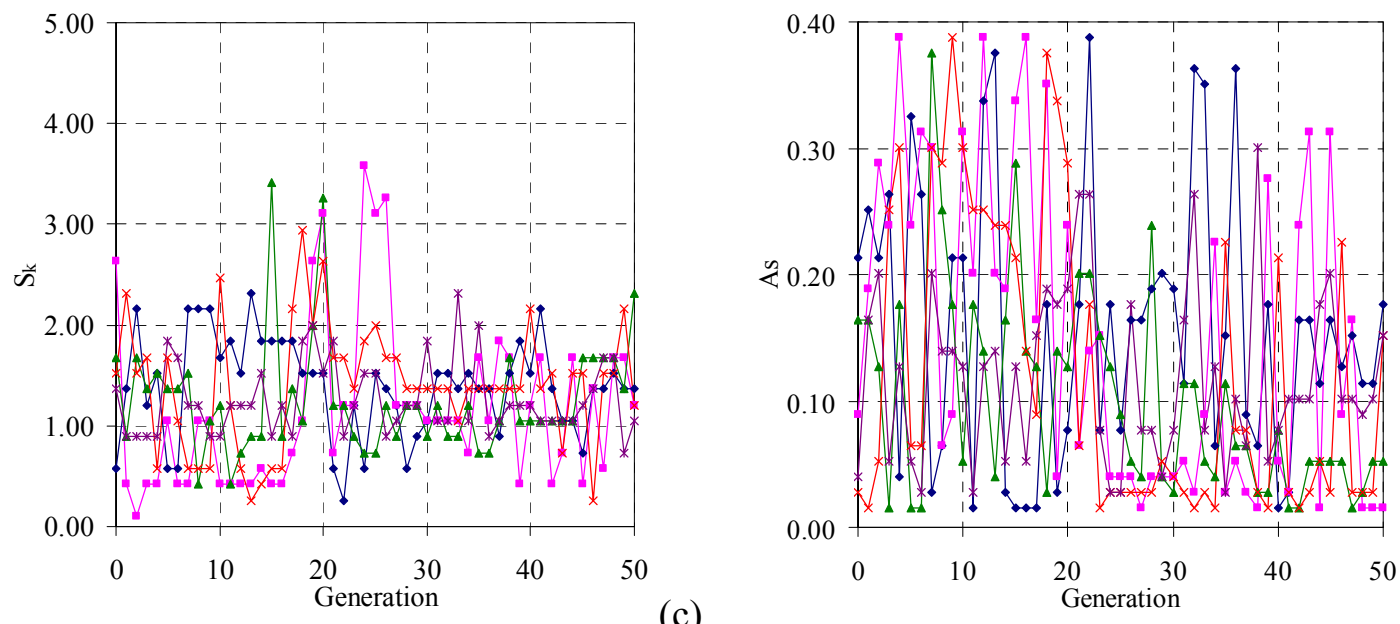

(d)
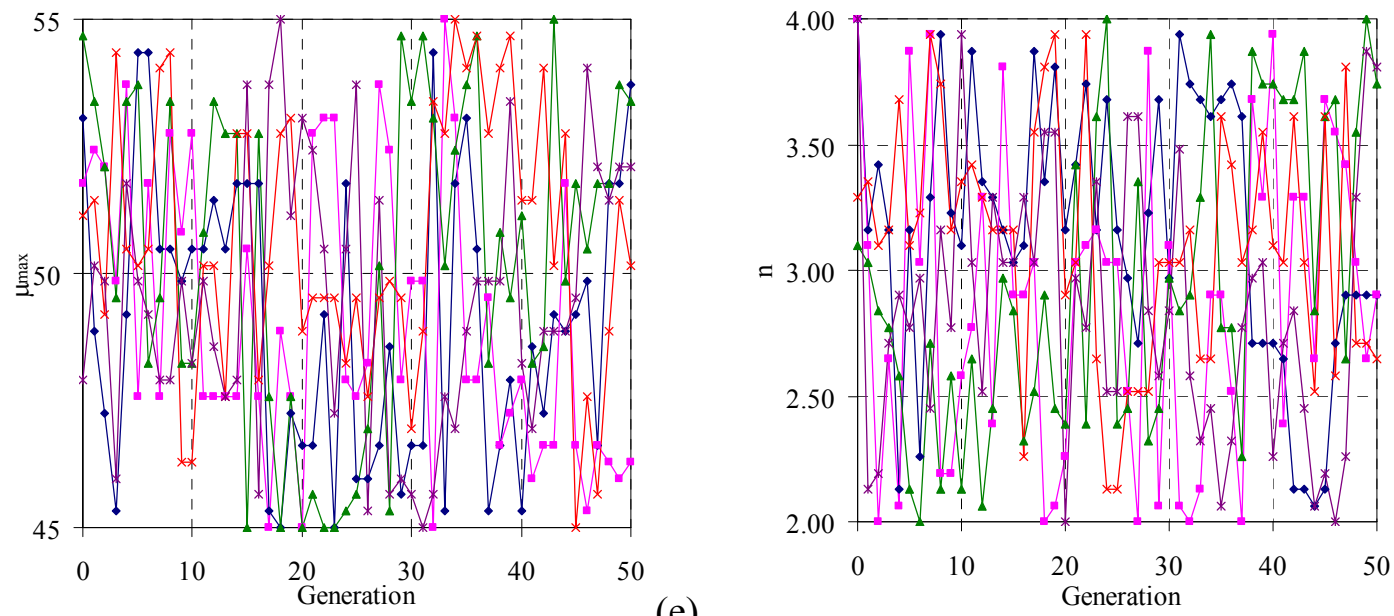

(e)

Fig. 9. Variations in values of parameters with respect to number of generations (first analysis). 

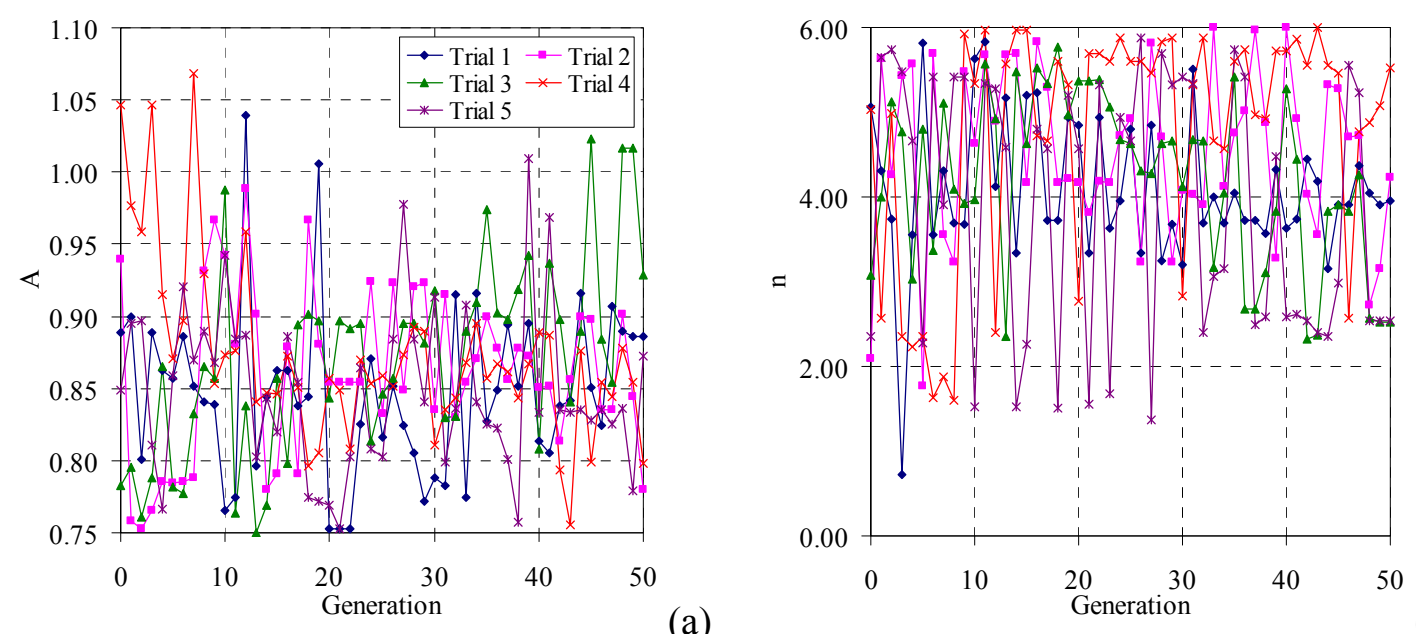

(a)

(b)
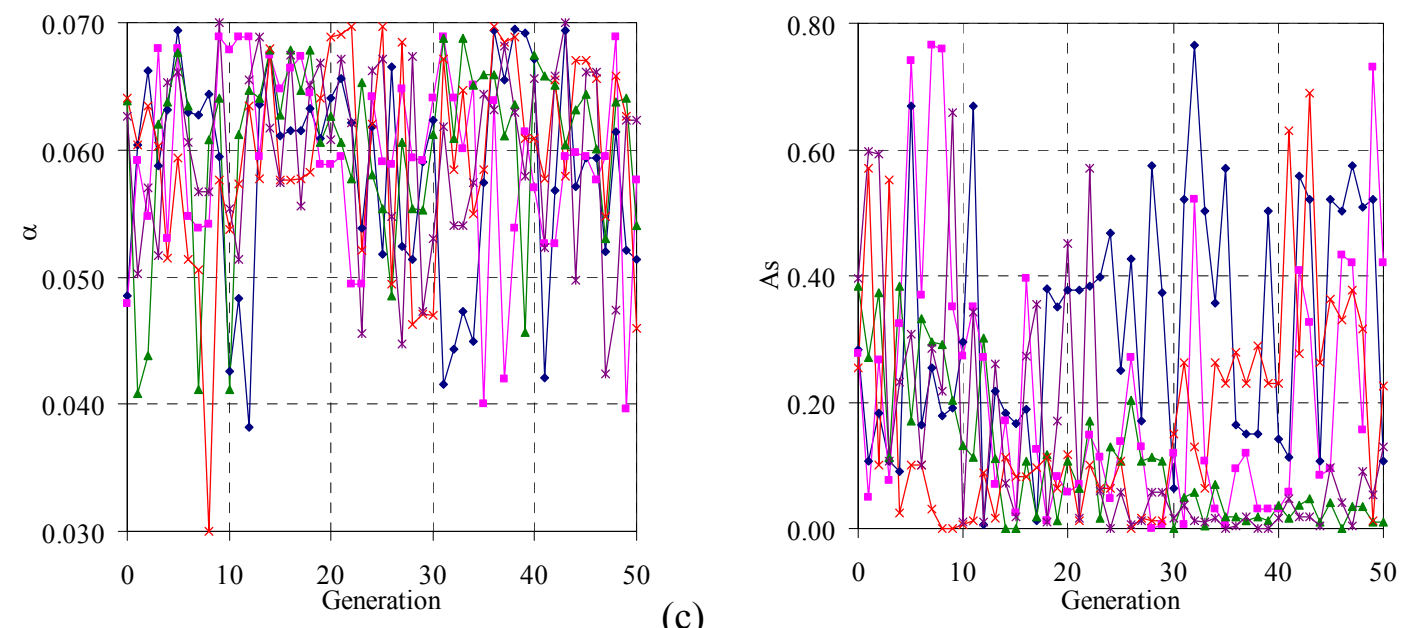

(d)
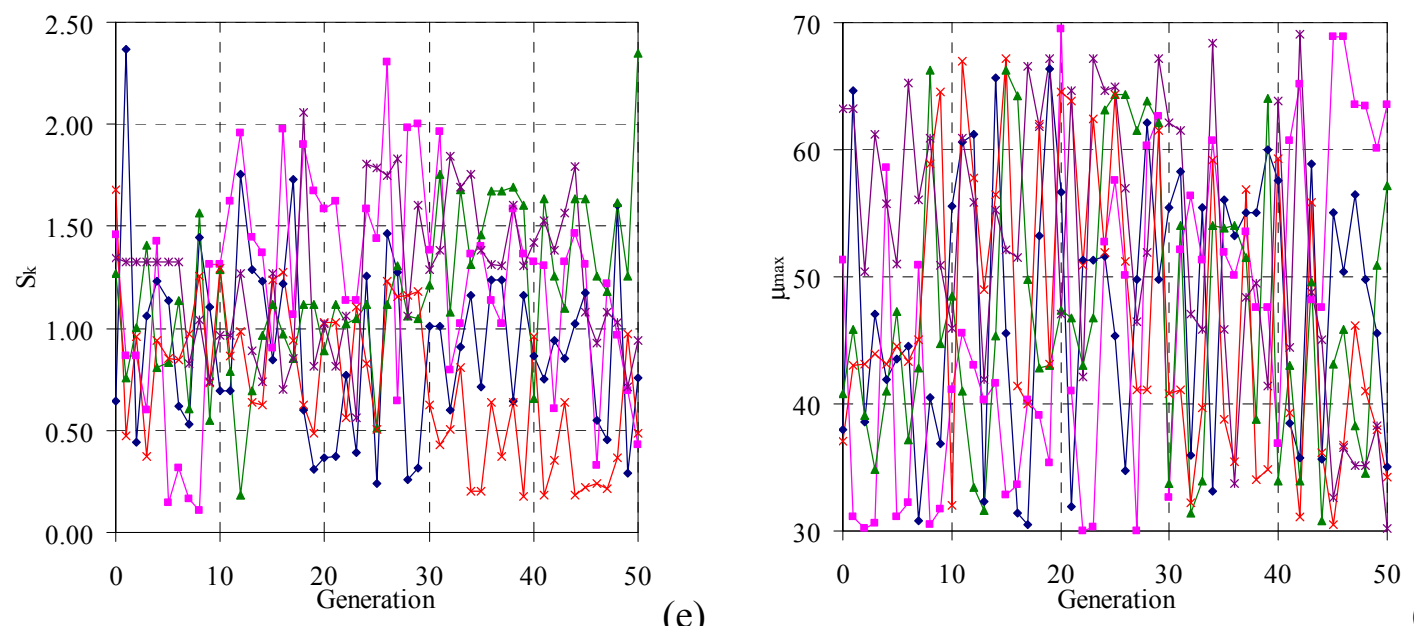

(e)

Fig. 10. Variations in values of parameters with respect to number of generations (second analysis). 


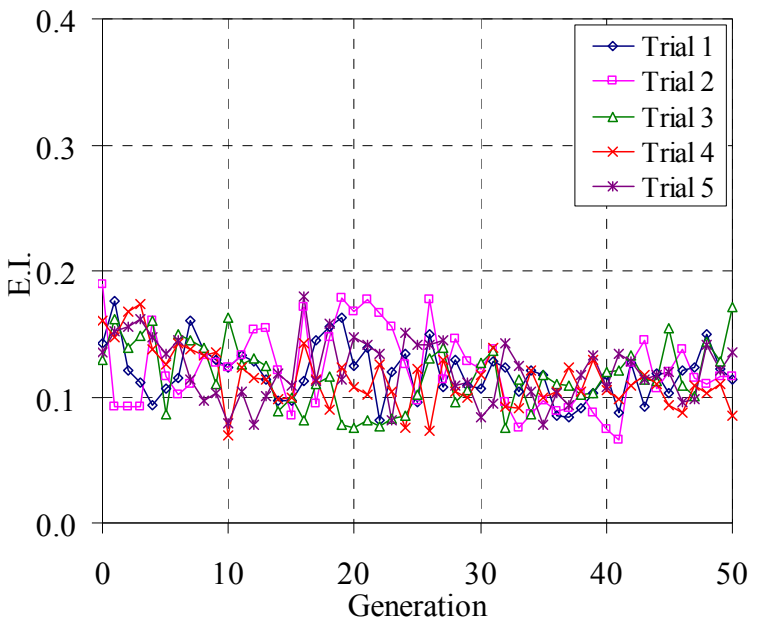

(a)

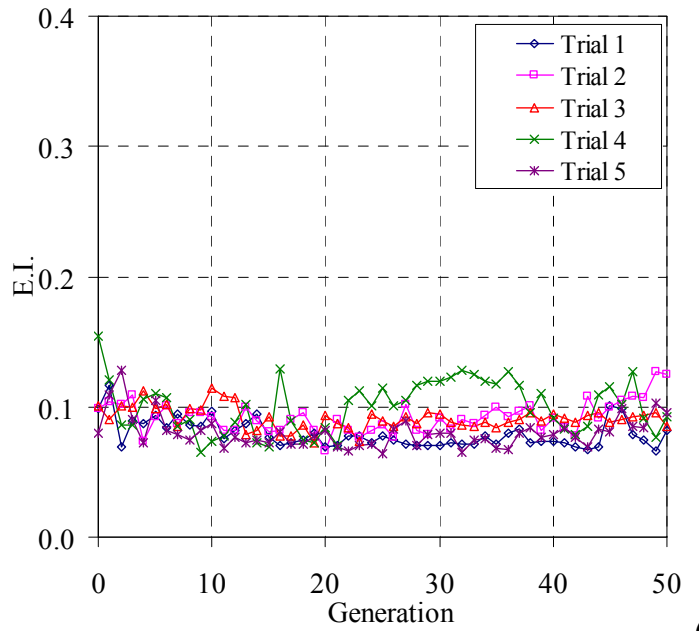

(b)

Fig. 11. Variations in smallest E.I. with respect to number of generations for (a) second analysis and (b) third analysis. 


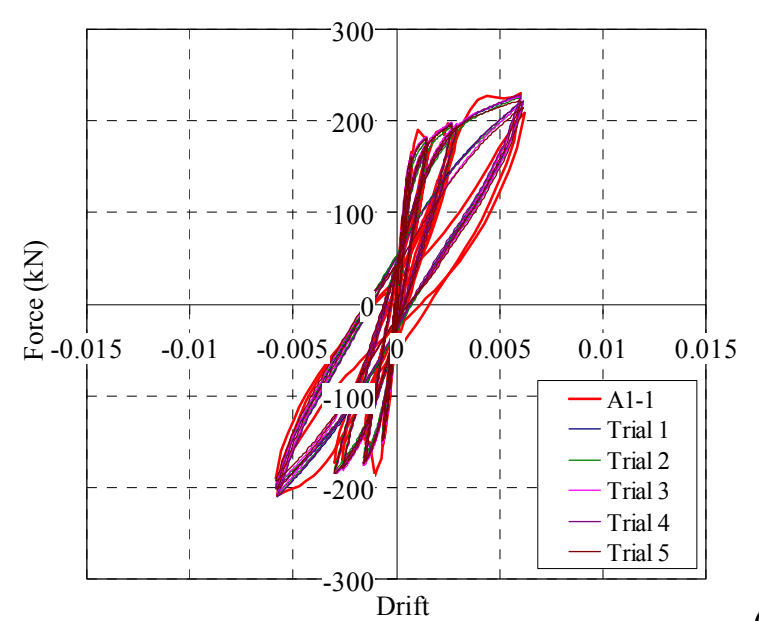

(a)

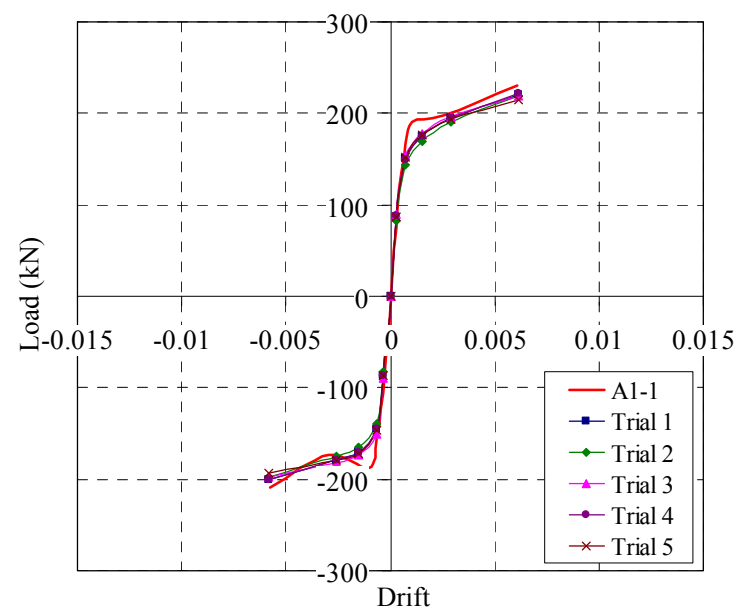

(b)

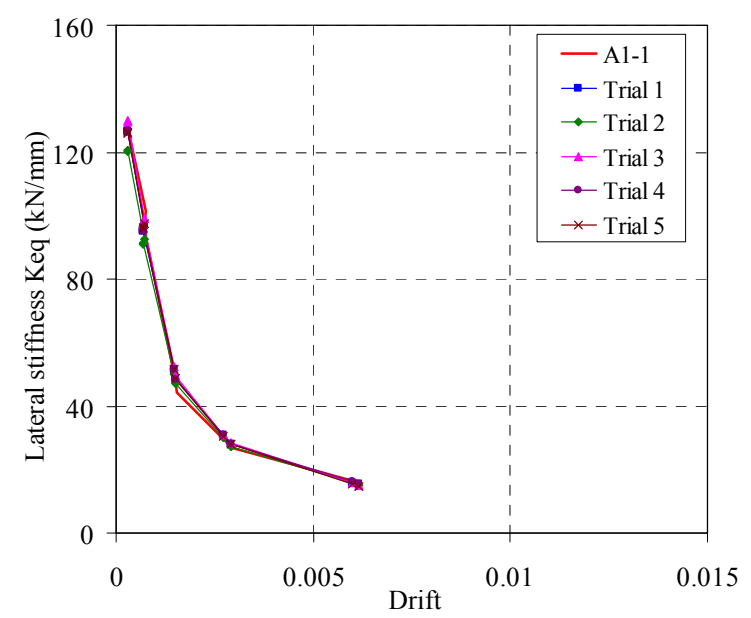

(c)

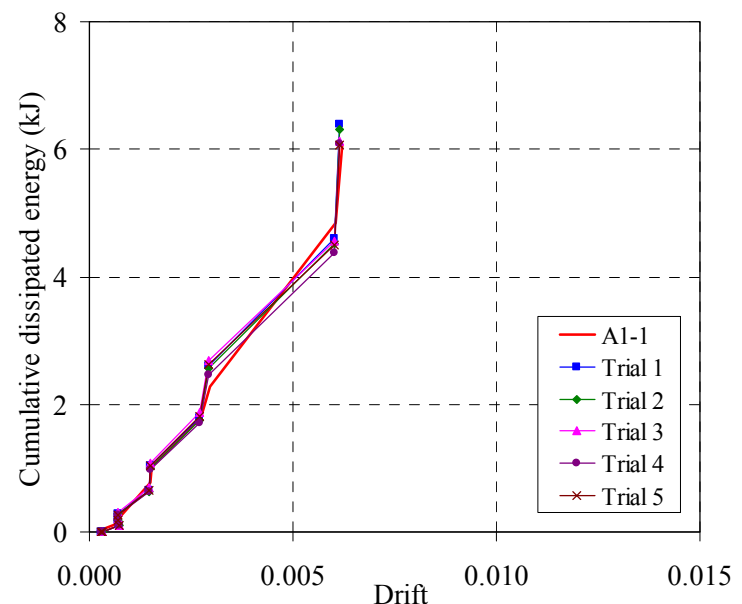

(d)

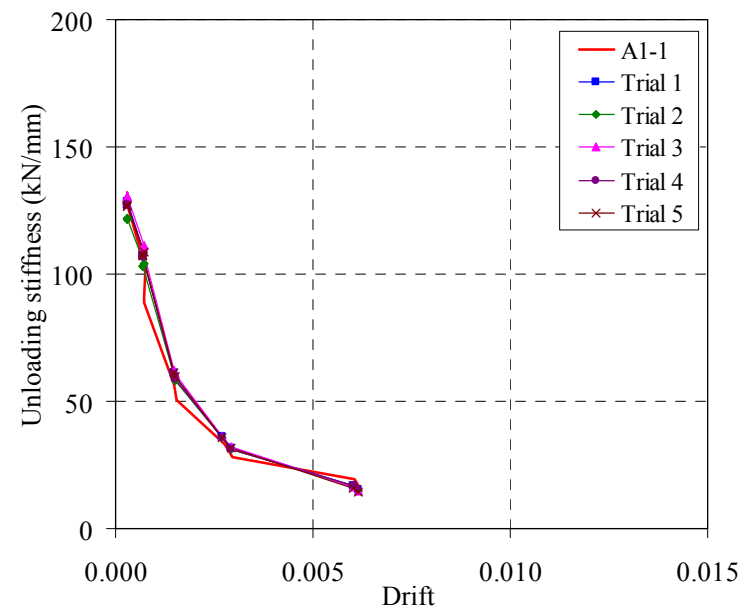

(e)

Fig. 12. Comparisons of experimental results with those of numerical simulation for wall A1-1: (a) hysteresis curves, (b) strength, (c) stiffness degradation, (d) cumulative dissipated energy, and (e) unloading stiffness. 

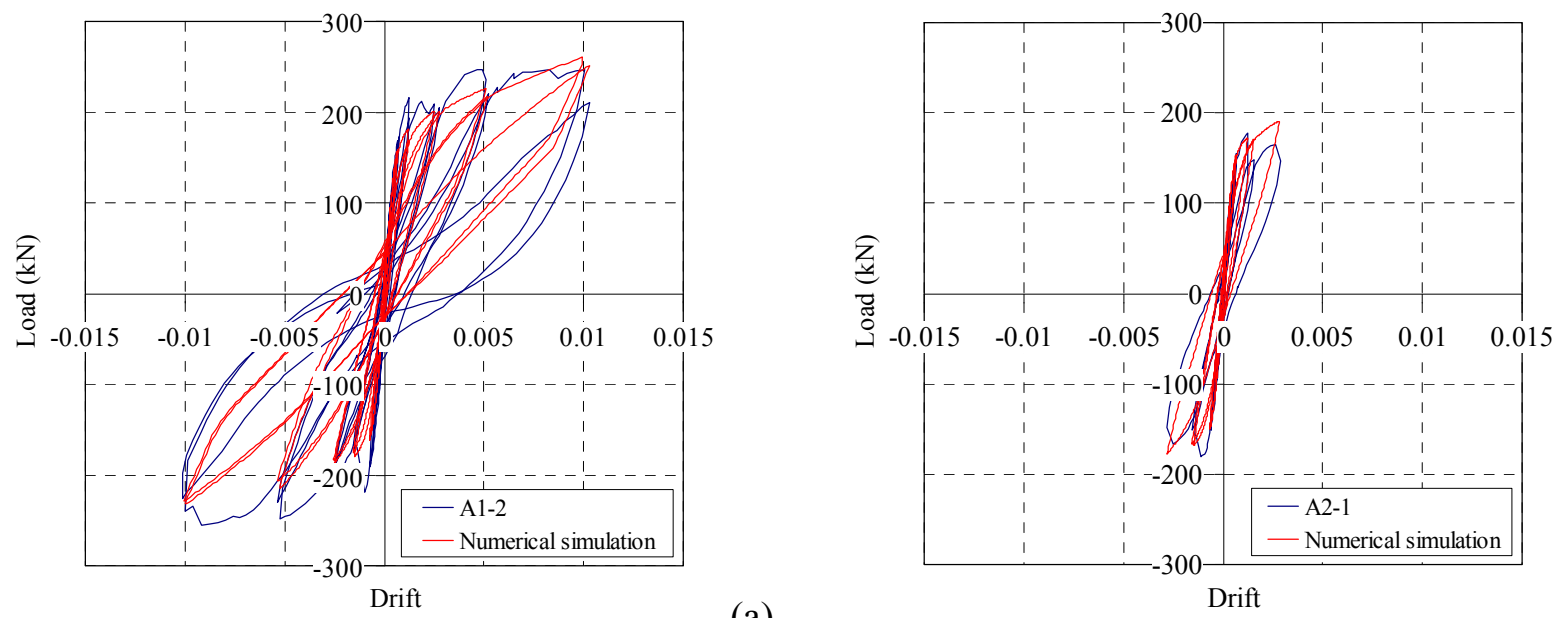

(a)

(b)

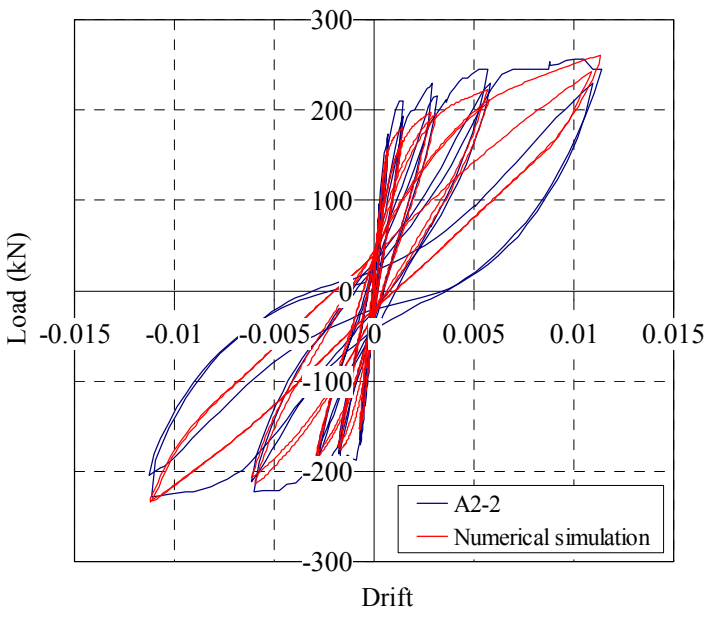

(c)

Fig. 13. Comparison of simulated and experimental hysteretic curves for walls: a) A1-2, c) A2-1, and c) A2-2. 


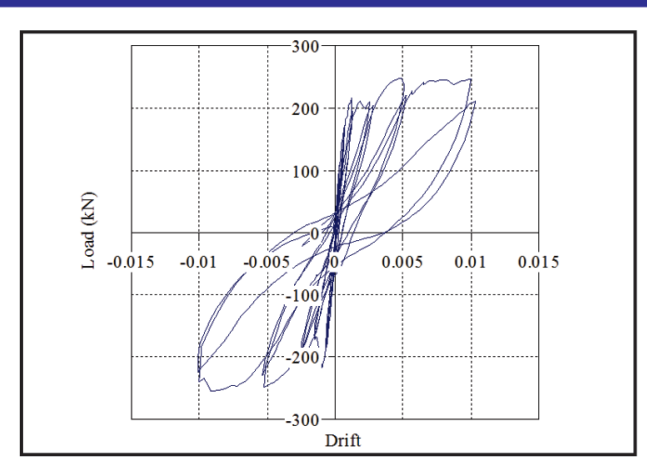

Hysteretic responses

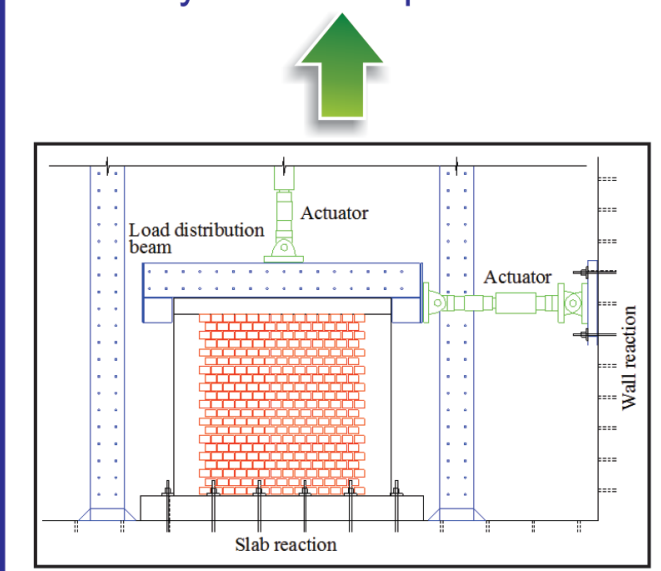

Test on walls

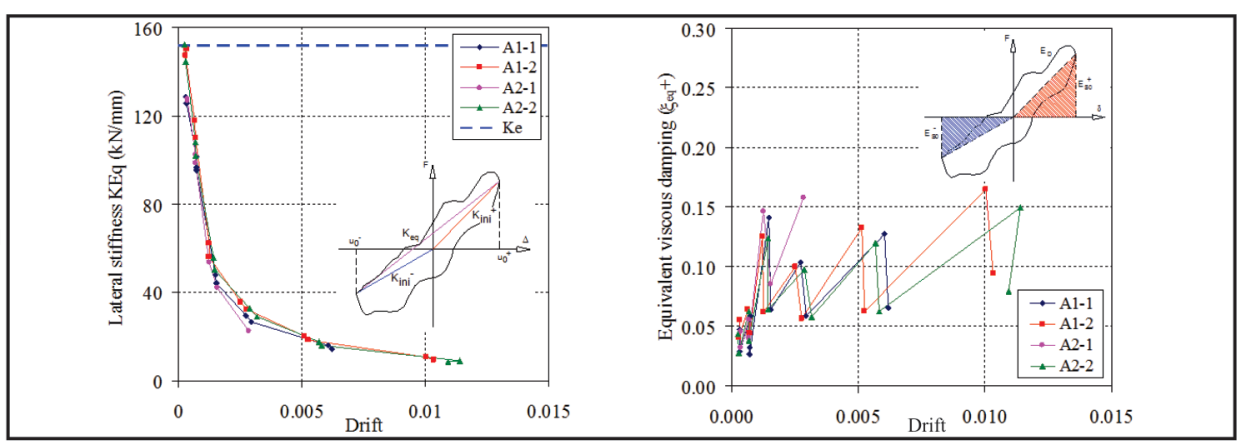

Structural characteristics

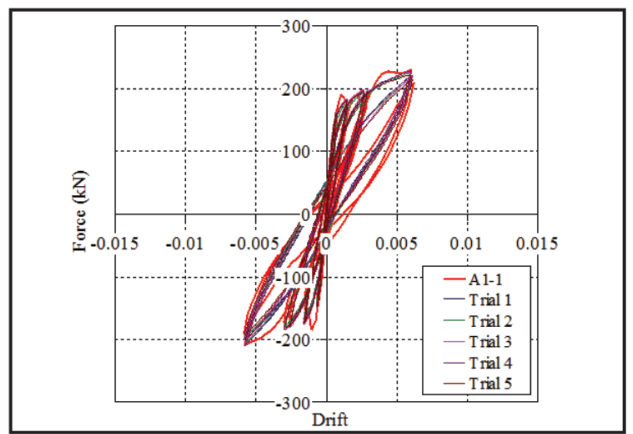

Test vs. Numerical simulation

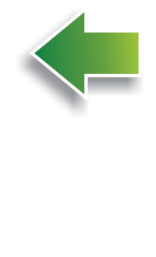

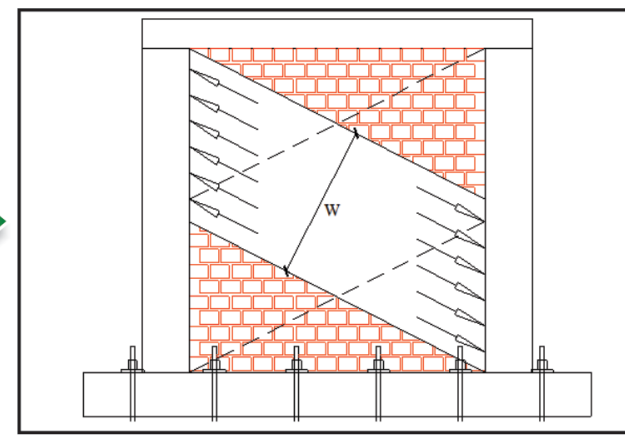

Numerical model

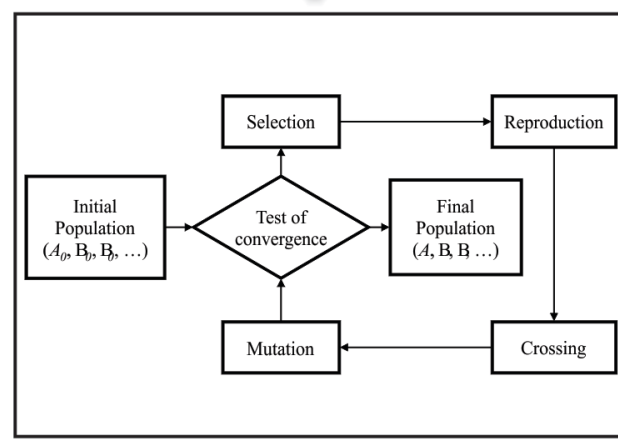

GA calibration 